\title{
A predictive strategy based on special points for evolutionary dynamic multi-objective optimization
}

\author{
Qingya Li · Juan Zou · Shengxiang Yang · Jinhua Zheng · Gan Ruan
}

Received: date / Accepted: date

\begin{abstract}
There are some real-world problems in which multiple objectives conflict with each other and the objectives change with time. These problems require an optimization algorithm to track the moving Pareto front or Pareto set over time. In this paper, we propose a predictive strategy based on special points (SPPS) which consists of three mechanisms. The first one is that the non-dominated set is predicted directly by feed-forward center points, which can eliminate many useless individuals predicted by traditional prediction using feed-forward center points. The second one is that a special point set(such as boundary point, knee point, etc.) is introduced into the predicted population which can track Pareto front or Pareto set more accurately. The third one is the adaptive diversity maintenance mechanism based on boundary points and center points. The mechanism can introduce diverse individuals of the corresponding number according to the degree of difficulty of the problem to keep the diversity of the population. The number of these diverse individuals is strongly related to the center points. Then, they are generated evenly throughout the decision space between the boundary points. The proposed strategy is
\end{abstract}

Qingya Li · Juan Zou · Jinhua Zheng · Gan Ruan

Key Laboratory of Intelligent Computing and Information Processing, Ministry of Education, Information Engineering College of Xiangtan University, Xiangtan, Hunan Province, China

E-mail: zoujuan@xtu.edu.cn

Jinhua Zheng

School of Computer Science and Technology, Hengyang Normal University, Hunan, China

Shengxiang Yang

The Center for Computational Intelligence (CCI), School of Computer Science and Informatics, De Montfort University, Leicester LE1 9BH, UK compared with the four other state-of-the-art strategies. The experimental results show that SPPS can do well for dynamic multi-objective optimization.

Keywords Evolutionary dynamic multi-objective optimization · Prediction · Boundary point · Knee point · Adaptive diversity maintenance strategy

\section{Introduction}

In real life, there are some problems whose multiple objectives conflict with each other and vary from time to time. These kinds of problems are called dynamic multiobjective optimization problems(DMOPs)[1]. Because evolutionary algorithms can achieve good results when dealing with DMOPs, they are applied widely in many areas, such as scheduling [4], [34], control [5], wireless network design [6], machine learning [7], [8] and constrained optimization [9].

The mathematical form of DMOPs is as follows:

$$
\begin{cases}\min _{x \in \Omega} F(x, t)=\left(f_{1}(x, t), f_{2}(x, t), \ldots, f_{m}(x, t)\right)^{T} \\ \text { s.t. } \quad g_{i}(x, t) \leq 0, i=1,2, \ldots, p \\ & h_{j}(x, t)=0, j=1,2, \ldots, q\end{cases}
$$

where $x=\left(x_{1}, x_{2}, \ldots, x_{n}\right)$ is the $\mathrm{n}$-dimensional decision vector whose domain of definition is $\Omega$, $\mathrm{t}$ represents time variable, $F=\left(f_{1}, f_{2}, \ldots, f_{m}\right)$ is the m-dimensional objective vector, $g$ represents p-dimensional inequality constraints, and h is q-dimensional equality constraints. The optimal tradeoff solution set is called the Pareto set (PS) in decision space and Pareto front (PF) in the objective space.

The traditional static optimization algorithms have some difficulty in dealing with DMOPs. While we use static algorithms, the population can gradually converge to current environment so that the genes of pop- 
ulation become single, which causes that the population loses diversity. However, the objectives of DMOPs can vary over time, which causes that the environment varies with time. As the population loses the diversity, it can not adapt to the changed environment, which results in a very slow convergence towards PF [33]. Some researchers adjust the static algorithm to adapt to the dynamic environment. The simplest means to deal with DMOPs is increasing the diversity of the population such as hyper mutation methods [34], employing multiple populations and parallel computing [28], [29], and applying different crossover and mutation operators [31]. However, there is some blindness in increasing the diversity of the population, since the diversity method does not guide the population to evolve toward the direction of convergence to PF.

Thus, some researchers have introduced other methods such as random initialization method [14]-[16], [34], the memory strategy [17]-[21], [34], [36], [37] and the prediction strategy [22]-[25], [38]-[43]. The memory strategy responds to environmental changes by memorizing previous historical information. For periodic problems, this strategy can perform well. But for non-periodic problems, the effect is bad. The prediction strategy can predict the optimal solutions after an environmental change by using the previous historical information. It has a good performance for a variety of problems. How to get a more accurate prediction to PF or PS after an environmental change is a focus of today's research. In 2006, Hatzakis and Wallace proposed a feed-forward strategy(FPS) [38] which can predict the boundary points in the new environment by memorizing some historical boundary point information to achieve a fast convergence. However, it has some difficulty in predicting the whole PF just by boundary points. In 2013, Zhou and Jin et al. proposed a population prediction strategy, which predicts the whole population by a center point and a manifold. When dealing with DMOPs using PPS [39], the effect of the later stage is quite good. However, at the early stages, the effect is a little worse. The reason of the situation is that the accurate prediction of the center point needs to accumulate experience. At the early stages, accumulation of experience is insufficient, but at the later stage, experience accumulated is enough. In 2015, Wu and Jin et al. proposed a directed search strategy [40] which predicts the whole population by feed-forward center points. This method performs well. But many useless individuals are introduced into the predicted population by predicting the whole population with the method of feed-forward center points. In 2016, Muruganantham and Tan et al. proposed a prediction method via Kalman Filter which can track PF accurately [32]. In 2017, Qian and Ye et al. combined immune system and evolution system to propose a micro-cloning dynamic multiobjective algorithm with an adaptive change reaction strategy [41]. The idea of the algorithm is innovative and the effect is good for DMOPs.

In view of the above shortcomings, this paper presents a new prediction method based on some special points. Its main contributions are as follows:

1. The non-dominated set can be directly predicted by using the feed-forward center points, and some useless individuals, which are introduced by using the feed-forward center method to predict the total population directly, are eliminated.

2. A special point set introduced into the population can better track the PF, thus accelerating the convergence of the population.

3. An adaptive diversity maintenance strategy based on boundary points and center points is proposed, which can introduce the individuals of different numbers according to the degree of difficulty of the problem. Moreover, these diverse individuals can be distributed evenly throughout the decision space between the boundary points.

The rest of paper is organized as follows. Section 2 presents some related work. Section 3 describes SPPS in detail. Section 4 gives the experimental results and analysis. Section 5 outlines the conclusions and future work.

\section{Related work}

2.1 A general framework of dynamic multi-objective genetic algorithm

The dynamic framework is as follows:

1. Initialize the population and set the relevant parameters.

2. Detect the environmental change. If an environmental change is found, go to step 4; if not, then go to step 3.

3. Optimize the problem by an evolutionary algorithm.

4. Take a certain response strategy such as re-initialization, memory, prediction, etc. to respond to the environmental change.

5. Judge the termination conditions. If not terminated, then go to the second step; if terminated, then exit.

\subsection{Special points}

Many researchers have tried to find the local points and regions with special significance on the PF or PS 


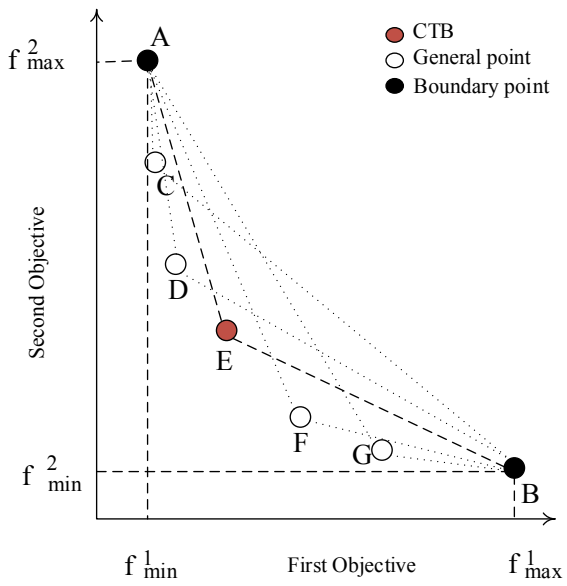

Fig. 1 Boundary point and CTB schematic.

[54], [55], [56], [59], [60]. Now we introduce some special points on the Pareto front. If not specified below, The problems in this paper are the minimum problems.

\subsubsection{Boundary point}

The boundary point has been of great interest to researchers. In [38], the boundary points and other points are predicted to represent the PF. For minimum problems, the boundary points are the individuals which have the smallest value in a dimension in the objective space. As shown in Fig. 1, A, B, C, D, E, F and G are seven non-dominated individuals in the non-dominated set. A and B are the boundary individuals (points) in the first and second dimension, respectively. If the dimensions of the objective space is 3 or over 3 , the number of the boundary points will be 3 or over 3 . That means that the number of the boundary points is equal to dimensions of the objective space.

\subsection{2 $C T B$}

CTB is the close-to-boundary point whose sum of the distances to the boundary points is the smallest. The formula is as follows

$d=\min _{1 \leq j \leq M} \sum_{i=1}^{m}\left\|X_{i}-K_{j}\right\|$.

where $\mathrm{m}$ is the dimensions of the objective space. M represents the size of the non-dominated set. $X_{i}$ is the boundary point in the i-th dimension, and $K$ is the individual in the non-dominated set. $d$ represents the smallest sum of distances of the individual in non-dominated set to boundary points.

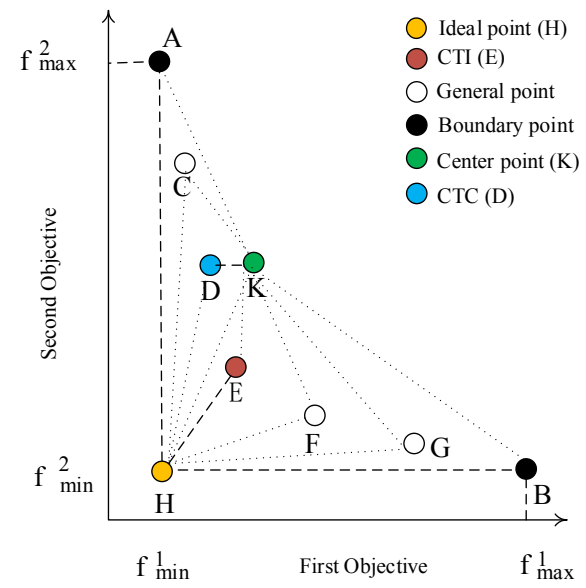

Fig. 2 CTC and CTI schematic.

As shown in Fig. 1, E is the point whose sum of the distances to the boundary points is the smallest, so $\mathrm{E}$ is the CTB.

\subsection{3 $C T C$}

CTC is the close-to-center point which means the point whose distance is the smallest to the center point. In [58], CTC is used as the represent point of a region in $\mathrm{PF}$. The center point has been widely applied in the prediction strategy [39], [40], [43], [48], [49], [58]. The formula of center point is as follows:

$C_{k}=\frac{1}{|P|} \sum_{x_{k} \in P} x_{k}$

where $k=1,2, \ldots, n . n$ is the dimensions of the decision space. $P$ is the population, and $x$ is an individual in the population. $|P|$ is the size of the population. As shown in Fig. 2, A, B, C, D, E, F and G are seven nondominated individuals in the non-dominated set. A and $\mathrm{B}$ are boundary individuals, and $\mathrm{K}$ is the center point of non-dominated set. $\mathrm{K}$ is calculated by formula (2) in decision space, and then mapped into the objective space. Thus $\mathrm{K}$ is not necessarily the center of PF. The Euclidean distance of $\mathrm{D}$ to $\mathrm{K}$ is the smallest, so $\mathrm{D}$ is CTC.

\subsubsection{CTI}

In [38], CTI, like the boundary points, is predicted to represent the PF. CTI is the close-to-ideal point whose distance to the ideal point is the smallest among the non-dominated set. The ideal point is the point whose value of each dimension is the smallest among the non- 


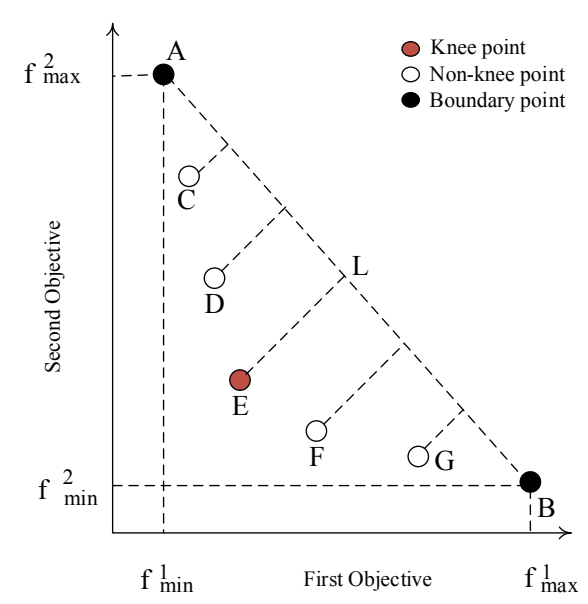

Fig. 3 Knee point schematic.

dominated set [38]. Assuming that $\mathrm{H}$ is the ideal point, the formula is as follows:

$H_{i}^{*}=\min \left\{f\left(N o n P_{i}^{1}\right), f\left(N o n P_{i}^{2}\right), \ldots, f\left(N o n P_{i}^{M}\right)\right\}$.

where $i=1,2, \ldots, m . \mathrm{m}$ is the dimensions of the objective space. $\mathrm{M}$ is the size of the non-dominated set. $f\left(N_{\text {on }} P_{i}^{M}\right)$ denotes the value of the i-th dimension of the M-th individual in the non-dominated set. As shown in Fig. 2, $\mathrm{H}$ is the ideal point. Since $\mathrm{E}$ is the individual whose distance is smaller than the other individuals in the non-dominated set, $\mathrm{E}$ is the CTI.

\subsubsection{Knee point}

The knee point on the Pareto optimal front refers to the point with the maximum marginal rates of return. It means that there is a small improvement in one objective, accompanied by severe degradation of at least one other objective. In addition, Zhang [44] proved that the knee point is better than the other points on the Pareto front for the metric of HV [53]. The higher the $\mathrm{HV}$, the better the convergence and distribution of the population.

There are many definitions for the knee point [44][47]. In this paper, we use the definition of Das [45] and Zhang [44]. As shown in Fig. 3, A, B, C, D, E, F and $\mathrm{G}$ are seven non-dominated points, where $\mathrm{A}$ and $\mathrm{B}$ are the boundary points in the non-dominated set. The perpendicular of C, D, E, F, G to the line L formed by A, B represents the distance, as shown in formula (5). $\mathrm{E}$ has the longest distance from the straight line L, so $\mathrm{E}$ is the knee point.

The mathematical formula of straight line $\mathrm{L}$ is as follows:

$a x+b y+c=0$.

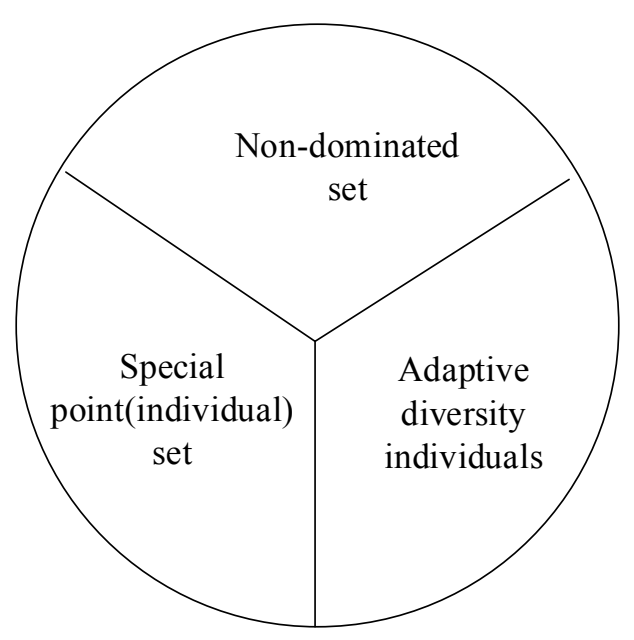

Fig. 4 Population structure schematic.

The point is $\mathrm{K}$, and the coordinate is $\left(x_{k}, y_{k}\right)$, so the distance of the point $\mathrm{K}$ to the line $\mathrm{L}$ is as follows:

$d(K, L)=\frac{\left|a x_{K}+b y_{K}+c\right|}{\sqrt{a^{2}+b^{2}}}$.

For the minimum problem, though only the convex knee region is of special interest [45]. In this paper, we use the knee point to represent the point whose distance to the extreme line is the longest among the non-dominated set. Thus, the formula (5) is still used. From formula (5), we can imagine that when the objective number of the optimization problem is greater than two, the line consisting of the boundary points becomes a plane or hyperplane, and it becomes the distance of the point to the plane or hyperplane.

\section{Predictive strategy based on special points}

Some prediction strategies are often used to predict moving PF or PS. In this paper, we propose a prediction strategy based on special points. The predicted population consists of three parts. The first part is a special point set which can make the predicted population track PF more accurately and improve the convergence speed towards the PF (PS). The second part is the non-dominated set predicted by the feed-forward center points which can eliminate many useless individuals by predicting the whole population with the method of feed-forward center points. The third part is the adaptive diverse individuals generated by the adaptive diversity stategy. The population structure is shown as Fig. 4. 


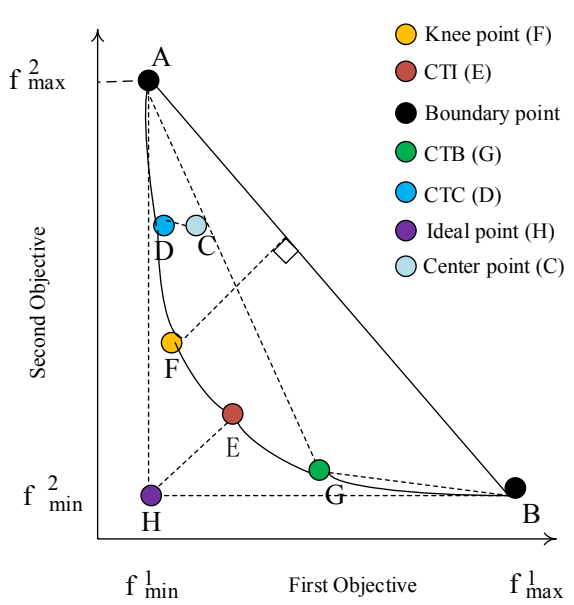

Fig. 5 Special points schematic in the case of bi-objective

\subsection{Special point set}

The special point set includes five kinds of special points. They are the boundary points, CTB, CTC, CTI and knee point. Each of them has a special significance. They are grouped together to represent PF. SPPS can predict the location and distribution of $\mathrm{PF}$ after an environmental change by predicting the special point set. They are shown in Fig. 5. A and B are two boundary points, and $\mathrm{G}$ is $\mathrm{CTB}$. $\mathrm{H}$ is the ideal point, and $\mathrm{E}$ is CTI. C represents the center point, and D is CTC. F is the knee point. $\mathrm{H}$ (Ideal point) and $\mathrm{C}$ (center point) are not included in the special point set. They are only used to get CTI and CTC. The special point set is predicted by autoregressive(AR) model [39].

3.2 Predicting the non-dominated set by feed-forward center points

The method of feed-forward center points [39], [40], [43], [48], [49] has been widely used to predict the population. However, most of these algorithms are used to predict the whole population with feed-forward center points. The predicted whole population includes many useless individuals in addition to non-dominated individuals. Therefore, we only predict the non-dominated individuals using the method of feed-forward center points. The prediction formula is as follows:

$\operatorname{NonInd}_{k}^{t+1}=C_{k}^{t}-C_{k}^{t-1}+N o n \operatorname{Ind} d_{k}^{t}+\operatorname{Gaussian}(0, d),(6)$

where $k=1,2, \ldots, n, \mathrm{n}$ represents the dimensions of the decision vector. $\mathrm{t}$ is the time step. NonInd $d_{k}^{t+1}$ and NonInd $d_{k}^{t}$ represent the non-dominated individual int $\mathrm{t}+1$ step and $\mathrm{t}$ step in the $\mathrm{k}$-th dimension, respectively.

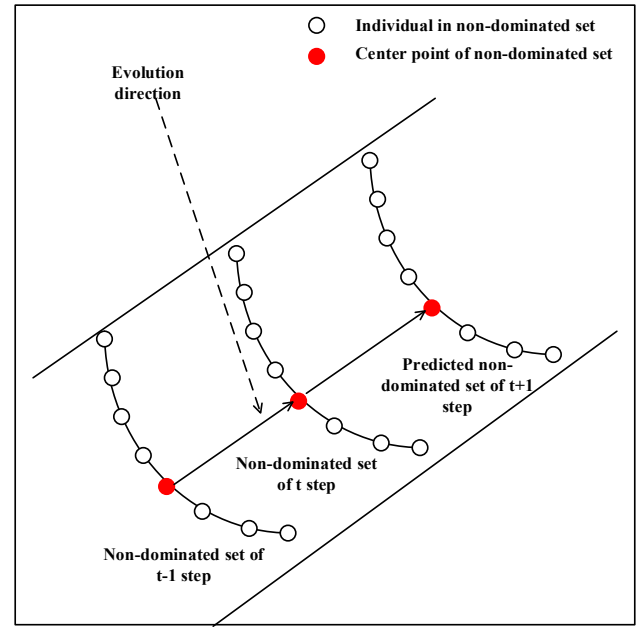

Fig. 6 Schematic diagram of predicting non-dominated set by feed-forward center points.

Gaussian $(0, d)$ denotes a Gaussian perturbation with mathematical expectation 0 and the variance d. $C_{k}^{t}$ and $C_{k}^{t-1}$ are the center point in t step and t- 1 step in the kth dimension, respectively. $C_{k}^{t}$ can be shown as follows:

$C_{k}^{t}=\frac{1}{\left|P_{\text {Non-dom }}^{t}\right|} \sum_{\text {NonInd }}^{t} \in P_{\text {Non-dom }}^{t} \operatorname{NonInd}_{k}^{t}$

where $\left|P_{N o n-d o m}^{t}\right|$ represents the cardinality of the nondominated set.

As shown in Fig. 6, the hollow circles on the arc lines represent the non-dominated individuals. The red circles represent the center points of the non-dominated sets, and the lines between the center points represent evolutionary directions. The non-dominated set of $t+1$ time step can be predicted by means of the nondominated set of the $t$ time step plus the evolution direction obtained by the method of center point $t$ time step minus center point of $\mathrm{t}-1$ time step. It is not an accurate prediction and Gaussian perturbation is a simple local search process, so Gaussian $(0, d)$ is added.

\subsection{Adaptive diversity maintenance strategy}

The diversity maintenance mechanism plays an important role in the dynamic strategy. In the dynamic environment, the environment changes constantly with time. In every period of the environment, the population evolves in a direction that is adapted to the environment. Thus, the genes of the population become single. When the environment changes, the population can not adapt well to the environment. Therefore, in this case, we need to introduce some diverse individuals, which can make the new population quickly adapt 


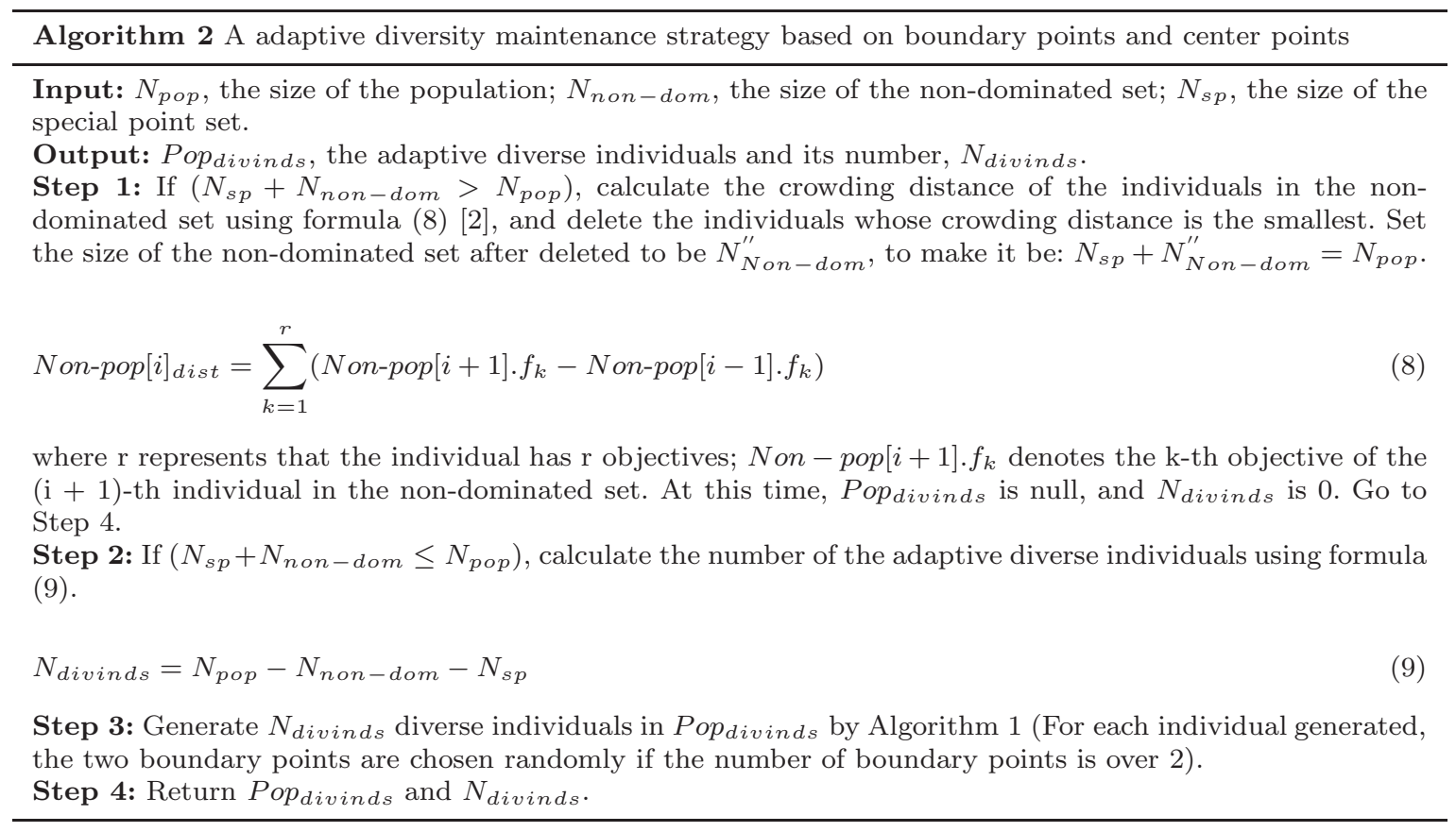

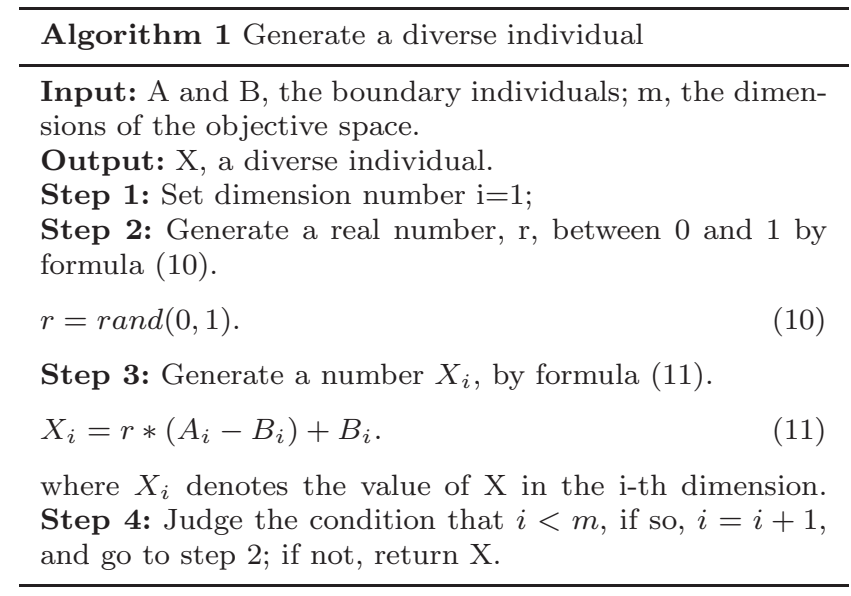

to the environment. The diversity maintenance mechanism plays the role of introducing diverse individuals when environment changes.

In this paper, an adaptive diversity maintenance mechanism is proposed which can introduce the diverse individuals of corresponding number according to the degree of difficulty of the problem. The number of these diverse individuals is strongly related to the size of the non-dominated set predicted by the feed-forward center points. However, the diverse individuals are generated based on the boundary points.

The detailed steps are as shown in Algorithm 2. Normally, $N_{\text {pop }}$, the size of the population, is fixed. And $N_{s p}$, the size of the special point set, is also fixed. Therefore, the value of $N_{\text {divinds }}$ is decided by $N_{n o n-d o m}$. According to formula (9), the greater the $N_{\text {non-dom, the }}$ smaller the $N_{\text {divinds }}$. Similarly, the smaller the $N_{\text {non-dom }}$, the greater the $N_{\text {divinds }}$.

In general, when the multi-objective optimization problem is particularly easy, the optimal solution will be very easy to predict. Meanwhile, the diverse individuals used to keep diversity are not so important and more diverse individuals will affect the convergence rate of the population. At this time, $N_{\text {divinds }}$ in this strategy is relatively small, or even likely to be 0 , which is consistent with the general features above. When the optimization problem is difficult, the predicted nondominated set is no longer accurate. In this case, a number of diverse individuals are needed to keep the diversity, and then accelerate the convergence of the population. Consistently, the value of $N_{\text {divinds }}$ in this case is also large, just to maintain the diversity of the population.

\subsection{Detailed description of SPPS}

SPPS is under the framework of the dynamic multiobjective evolutionary algorithm. After an environmental change, SPPS initializes the population so that the population can respond quickly to the environmental change. A detailed description of SPPS is shown in Algorithm 3 . 
Algorithm 3 A prediction strategy based on special points

Initialization: number of time change $\mathrm{t}:=0$; generation counter $g t:=0$; total evolution generation number, gmax. Step 1: Detect environmental changes. If no change, go to step 7; if change, seek the non-dominated set of current population.

Step 2: Get special point set, $P o p_{s p}$. And its size, $N_{s p}$. Step 3: Calculate the center point in each dimension, $C_{k}^{t}$, using formula (7).

Step 4: Predict the non-dominated set after an environmental change using formula (6), set to be Pop $p_{n o n-d o m}$. The size is $N_{\text {non-dom }}$.

Step 5: Calculate the adaptive diverse individuals, Popdivinds and its size, $N_{\text {divinds }}$ using Algorithm 2.

Step 6: Get the new population Pop $_{t+1}=$ Pop $_{s p}+$ Pop non-dom + Pop divinds

Step 7: Optimize the population with optimization algorithm RM-MEAD [52].

Step 8: If $g t>$ gmax, output Pop $_{t}$, and end; or $g t:=$ $g t+1$, go to Step 1 .

\section{Experimental results and analysis}

\subsection{Test problems and performance indicators}

\subsubsection{Test problems}

In this paper, several commonly used dynamic multiobjective test problems are used, such as the FDA test suite [50], dMOP test suite [51], two variants of FDA5 and dMOP2 - FDA5iso and dMOP2iso [62], F5-F10 [39] and HE3-HE4[62]. Both the FDA and dMOP series are linearly related between decision variables. FDA5iso and dMOP2iso have the isolated PF based on FDA5 and dMOP2. F5-F10 and HE3-HE4 are the test problems whose decision variables are nonlinearly related. FDA4, FDA5iso and F8 are the three-objective problems, and the others are bi-objective problems. F9-F10 are the test problems which are more difficult to converge than the others.

\subsubsection{Performance indicators}

In our experimental studies, we adopted the performance metrics which could help deeply investigate the performance of algorithms, such as convergence and distribution.

(1) Modified Inverted Generational Distance(MIGD) Inverted Generational Distance(IGD)[5] has been widely used to measure both the convergence and distribution. Here, let $P F_{t}$ be a set of uniformly distributed Pareto optimal points of the $\mathrm{PF}$ in t time and let $P_{t}$ be an ap- proximation set of $\mathrm{PF}$ in $\mathrm{t}$ time. IGD metric is defined as follows,

$\operatorname{IGD}\left(P F_{t}, P_{t}\right)=\frac{\sum_{v \in P F_{t}} d\left(v, P_{t}\right)}{\left|P F_{t}\right|}$

where $d\left(v, P_{t}\right)=\min _{u \in P_{t}}\|F(v)-F(u)\|$ is the distance between $\mathrm{v}$ and $P_{t} .\left|P F_{t}\right|$ is the cardinality of $P F_{t}$.

Since the environment is dynamic, it is hard to say which algorithm is better between two algorithms in some situations if only using simply IGD [22]. MIGD metric $[36,39,57,48,49]$ is a modified version of IGD, which is defined as the average of the IGD values in some time steps over a run.

$M I G D=\frac{1}{|T|} \sum_{t \in T} I G D\left(P F_{t}, P_{t}\right)$

where $\mathrm{T}$ is a set of discrete time points in a run and $|T|$ is the cardinality of T. MIGD is also a comprehensive performance metric like IGD to evaluate the performance of algorithms regarding convergence and distribution. The smaller the value is, the better the performance of the algorithm is.

(2)Modified Hypervolume Difference(MHVD)

The Hypervolume Difference(HVD)[22,41,61] measures the gap between the hypervolume of the obtained $\mathrm{PF}$ and that of the true PF. let $P F_{t}$ be a set of uniformly distributed Pareto optimal points of the $\mathrm{PF}$ in $\mathrm{t}$ time and let $P_{t}$ be an approximation set of $\mathrm{PF}$ in $\mathrm{t}$ time.

$$
H V D\left(P F_{t}, P_{t}\right)=\left|H V\left(P F_{t}\right)-H V\left(P_{t}\right)\right|
$$

where $H V(S)$ is the hypervolume of a set $\mathrm{S}$. |.| denotes to get absolute value.

MHVD is a modified version of HVD like MIGD to IGD. MHVD is defined as the average of the HVD values in some time steps over a run.

$$
M H V D=\frac{1}{|T|} \sum_{t \in T} H V D\left(P F_{t}, P_{t}\right)
$$

where $\mathrm{T}$ is a set of discrete time points in a run and $|T|$ is the cardinality of $\mathrm{T}$. The reference point for the computation of hypervolume is $\left(Z_{1}^{t}+0.5, Z_{2}^{t}+0.5, \ldots, Z_{M}^{t}+\right.$ $0.5)$, where $Z_{j}^{t}$ is the maximum value of the $\mathrm{j}$-th objective of the true $\mathrm{PF}$ in $\mathrm{t}$ time; $\mathrm{M}$ is the number of objectives. MHVD is also a comprehensive metric like $\mathrm{HV}$ to evaluate both the convergence and distribution. The smaller the value is, the better the performance of the algorithm is.

\subsection{Parameter settings}

The strategies to compare with SPPS are as follows: (1) randomly initialize strategy (RIS), which randomly 
generates individuals in the feasible region of the decision space; (2) feed-forward prediction strategy(FPS) [38]; (3) population prediction strategy(PPS) [39]; (4) A micro-cloning dynamic multiobjective algorithm (mcDMOA), which is with an adaptive change reaction strategy [41].

The optimization algorithm uses RM-MEDA to optimize problems. Run 20 times independently on each problem, and there are 100 environmental changes in every run. Environmental change degree nt is 10 . The size of the population is 100 when dimensions of the objective space is 2. For FDA4, FDA5iso, F8 whose objective numbers are 3 , the size of the population is 200 . The dimensions of the decision space is 20 . The parameter $\underline{\mathrm{p}}$ is 3 , and the length of the history information sequence $\underline{M}$ is 23 in $\mathrm{AR}(\mathrm{p})$ modal.

Parameters in FPS: There are $3(\mathrm{~m}+1)$ predicted individuals. Seventy percent of the other individuals in the new population inherit the population in the last environmental change and the other $30 \%$ are generated randomly in search space $[36,48]$.

Parameters in mcDMOA: The total number of clones $N_{\max }=20$. The rate of selecting is set to be $\alpha=0.06$. The monitoring threshold $\eta$ is set to 0.01 and integer $p=20$ [41].

Parameters in SPPS: In the process of predicting the non-dominated set by feed-forward center points, set the Gaussian perturbation d to be 0.1 .

Environmental change detection: In every generation, select $5 \%$ of the individuals of the population to detect the environmental change. These individuals are checked one by one for discrepancy between their previous objective values and re-evaluated ones. If a discrepancy is found in one individual among them, we assume a change is successfully detected and there is no need to do further checks for the rest of population members [61].

\subsection{Comparison of performance evaluation results}

We divided 100 environmental changes into three stages in the experiment: the first stage (1st stage) included the first 20 environmental changes; the second stage (2nd stage) included the middle 40 environmental changes; the third stage (3rd stage) included the last 40 environmental changes. Mean and standard deviation of MIGD values and MHVD values are shown in Tables 1, 2, 3 and 4 , respectively. The best values are in bold face by comparison of the five algorithms. The Wilcoxon ranksum test [63] was carried out to indicate significance between different results at the 0.05 significance level.
4.3.1 Experimental results of comparison experiment on FDA, dMOP test suites and their variants, FDA5iso and dMOP2iso

As shown in Table 1, the five strategies are compared for MIGD metric on the FDA test suite, the dMOP test suite, FDA5iso and dMOP2iso whose decision variables are linearly related. The total stage represents all the environmental changes, which includes 100 environmental changes.

(1) For the total stage on two-dimensional problems, SPPS is slightly worse than FPS on FDA2 and dMOP1 whose PS are changeless. On dMOP3 and dMOP2iso, SPPS is slightly worse than mcDMOA, but better than three other strategies. For all the other problems, SPPS is better than the four other strategies. It indicates that SPPS has the ability to quickly respond to environmental changes. The results of RIS are the worst, which indicates that these prediction strategies are better than random strategy.

(2) For the first stage on two-dimensional problems, SPPS is slightly worse than FPS on dMOP1. On FDA1, dMOP2, dMOP2 and dMOP2iso, mcDMOA is better than the other strategies. In the other problems, SPPS is significantly better than RIS, FPS, PPS and mcDMOA.

(3) For the second stage on two-dimensional problems, SPPS is better than the other strategies for some problems. However, for the third stage, SPPS is worse than PPS on FDA1, dMOP2 and dMOP3.

(4) For FDA4 which is a three-dimensional problem, SPPS is worse than mcDMOA, but better than RIS, FPS and PPS at all stages. However, for FDA5iso which is also a three-dimensional problem more difficulty than FDA4, RIS is better than FPS, PPS, mcDMOA and SPPS.

Exploring its reason to know, both FPS and PPS require the accumulation of experience. Although special points in SPPS also need the accumulation of experience when they are predicted, the non-dominated set can be directly predicted not to accumulate experience. Coupled with the adaptive diversity maintenance mechanism of SPPS, SPPS converges faster than FPS and PPS. However, for the third stage, because the experience has enough accumulation, PPS is better than SPPS for some test problems. For dMOP1 and FDA2, FPS has the best effect. The reason is also easy to understand. dMOP1 and FDA2 are the problems whose PS are changeless with time and seventy percent of the individuals inherit the population in the last environmental change for FPS. So FPS is a hybrid strategy including memory strategy and prediction strategy. The reason may be that memory strategy has a very good 
Table 1 Mean and Standard Deviation of MIGD values of five strategies on FDA, dMOP test suites and their variants, dMOP2iso and FDA5iso. $\ddagger$ and $\dagger$ indicate SPPS performs significantly better than and equivalently to the corresponding algorithms, respectively.

\begin{tabular}{|c|c|c|c|c|c|c|}
\hline Problems & Statistic & RIS & FPS & PPS & mcDMOA & SPPS \\
\hline \multirow[t]{4}{*}{ FDA1 } & total & $1.3155(0.0303) \ddagger$ & $0.0516(0.0086) \ddagger$ & $0.0528(0.0091) \ddagger$ & $2.9277(0.00002) \ddagger$ & $0.0258(0.0048)$ \\
\hline & 1st stage & $1.2215(0.0752) \ddagger$ & $0.2090(0.0439) \ddagger$ & $0.2406(0.0461) \ddagger$ & $0.0074(0.0001)$ & $0.1002(0.0248)$ \\
\hline & 2nd stage & $1.3310(0.0414) \ddagger$ & $0.0151(0.0012) \ddagger$ & $0.0102(0.0010) \ddagger$ & $3.6213(0.00005) \ddagger$ & $0.0082(0.0001)$ \\
\hline & 3rd stage & $1.3447(0.0470) \ddagger$ & $0.0134(0.0008) \ddagger$ & $0.0062(0.0001)$ & $3.6213(0.0001) \ddagger$ & $0.0081(0.0001)$ \\
\hline \multirow[t]{4}{*}{ FDA2 } & total & $0.0500(0.0008) \ddagger$ & $0.0085(0.0007)$ & $0.0097(0.0008) \ddagger$ & $0.0260(0.00004) \ddagger$ & $0.0089(0.0004)$ \\
\hline & 1st stage & $0.0491(0.0011) \ddagger$ & $0.0198(0.0033) \ddagger$ & $0.0232(0.0032) \ddagger$ & $0.0206(0.00004) \ddagger$ & $0.0173(0.0022)$ \\
\hline & 2nd stage & $0.0503(0.0012) \ddagger$ & $0.0060(0.0003)$ & $0.0070(0.0007) \ddagger$ & $0.0273(0.00005) \ddagger$ & $0.0069(0.0002)$ \\
\hline & 3rd stage & $0.0501(0.0013) \ddagger$ & $0.0056(0.00003)$ & $0.0060(0.00004)$ & $0.0273(0.00004) \ddagger$ & $0.0069(0.0002)$ \\
\hline \multirow[t]{4}{*}{ FDA3 } & total & $1.7564(0.0655) \ddagger$ & $0.0645(0.0093) \ddagger$ & $0.0941(0.0158) \ddagger$ & $0.3441(0.0009) \ddagger$ & $0.0383(0.0076)$ \\
\hline & 1st stage & $1.5737(0.1248) \ddagger$ & $0.2084(0.0444) \ddagger$ & $0.3209(0.0780) \ddagger$ & $0.3220(0.0004) \ddagger$ & $0.1421(0.0362)$ \\
\hline & 2nd stage & $1.7709(0.1183) \ddagger$ & $0.0305(0.0034) \ddagger$ & $0.0420(0.0082) \ddagger$ & $0.3497(0.0015) \ddagger$ & $0.0140(0.0020)$ \\
\hline & 3rd stage & $1.8287(0.1104) \ddagger$ & $0.0303(0.0042) \ddagger$ & $0.0384(0.0068) \ddagger$ & $0.3489(0.0006) \ddagger$ & $0.0133(0.0025)$ \\
\hline \multirow[t]{4}{*}{ FDA4 } & total & $0.4566(0.0092) \ddagger$ & $0.1414(0.0034) \ddagger$ & $0.1307(0.0020) \ddagger$ & $0.0646(0.0014)$ & $0.1114(0.0030)$ \\
\hline & 1st stage & $0.4390(0.0210) \ddagger$ & $0.1629(0.0085) \ddagger$ & $0.1660(0.0082) \ddagger$ & $0.0650(0.0046)$ & $0.1317(0.0069)$ \\
\hline & 2nd stage & $0.4594(0.0151) \ddagger$ & $0.1376(0.0043) \ddagger$ & $0.1247(0.0028) \ddagger$ & $0.0631(0.0027)$ & $0.1077(0.0050)$ \\
\hline & 3rd stage & $0.4622(0.0113) \ddagger$ & $0.1386(0.0034) \ddagger$ & $0.1231(0.0028) \ddagger$ & $0.0659(0.0022)$ & $0.1054(0.0015)$ \\
\hline \multirow[t]{4}{*}{ dMOP1 } & total & $0.6386(0.0143) \ddagger$ & $0.0072(0.0012)$ & $0.0379(0.0515) \ddagger$ & $0.1067(0.00004) \ddagger$ & $0.0097(0.0021)$ \\
\hline & 1st stage & $0.6486(0.0346) \ddagger$ & $0.0195(0.0061)$ & $0.1413(0.2112) \ddagger$ & $0.0955(0.0002) \ddagger$ & $0.0301(0.0116)$ \\
\hline & 2nd stage & $0.6383(0.0279) \ddagger$ & $0.0043(0.0001)$ & $0.0209(0.0287) \ddagger$ & $0.1094(0.00004) \ddagger$ & $0.0049(0.0003)$ \\
\hline & 3rd stage & $0.6341(0.0186) \ddagger$ & $0.0043(0.0001)$ & $0.0057(0.00002) \dagger$ & $0.1095(0.00003) \ddagger$ & $0.0048(0.0003)$ \\
\hline \multirow[t]{4}{*}{ dMOP2 } & total & $1.6968(0.0541) \ddagger$ & $0.0622(0.0079) \ddagger^{\prime}$ & $0.0607(0.0102) \ddagger$ & $0.1061(0.0001) \ddagger$ & $0.0279(0.0040)$ \\
\hline & 1st stage & $1.6332(0.0875) \ddagger$ & $0.2552(0.0393) \ddagger$ & $0.2799(0.0518) \ddagger$ & $0.0969(0.0002)$ & $0.1067(0.0211)$ \\
\hline & 2nd stage & $1.7087(0.0922) \ddagger$ & $0.0170(0.0011 \ddagger)$ & $0.0111(0.0010) \ddagger$ & $0.1078(0.0001) \ddagger$ & $0.0094(0.0002)$ \\
\hline & 3rd stage & $1.7150(0.0672) \ddagger$ & $0.0159(0.0007) \ddagger$ & $0.0061(0.0001)$ & $0.1087(0.0002) \ddagger$ & $0.0091(0.0002)$ \\
\hline \multirow[t]{4}{*}{ dMOP3 } & total & $1.3215(0.0375) \ddagger$ & $0.0523(0.0065) \ddagger$ & $0.0527(0.0108) \ddagger$ & $0.0092(0.0001)$ & $0.0272(0.0041)$ \\
\hline & 1st stage & $1.2558(0.0824) \ddagger$ & $0.2124(0.0334) \ddagger$ & $0.2403(0.0553) \ddagger$ & $0.0091(0.0002)$ & $0.1076(0.0216)$ \\
\hline & 2nd stage & $1.3319(0.0538) \ddagger$ & $0.0149(0.0008) \ddagger$ & $0.0101(0.0009) \ddagger$ & $0.0092(0.0001) \ddagger$ & $0.0081(0.0001)$ \\
\hline & 3rd stage & $1.3423(0.0601) \ddagger$ & $0.0136(0.0008) \ddagger$ & $0.0062(0.0001)$ & $0.0092(0.0002) \ddagger$ & $0.0081(0.0001)$ \\
\hline \multirow[t]{4}{*}{ dMOP2iso } & total & $10.7386(0.2820) \ddagger$ & $0.2155(0.1217) \ddagger$ & $0.2229(0.0896) \ddagger$ & $0.1068(0.00002)$ & $0.1387(0.0513)$ \\
\hline & 1st stage & $10.7773(0.5784) \ddagger$ & $1.1028(0.6339) \ddagger$ & $0.9841(0.4670) \ddagger$ & $0.0941(0.00003)$ & $0.7052(0.2672)$ \\
\hline & 2nd stage & $10.8313(0.3088) \ddagger$ & $0.0047(0.0006) \dagger$ & $0.0150(0.0069) \ddagger$ & $0.1099(0.00003) \ddagger$ & $0.0041(0.0001)$ \\
\hline & 3rd stage & $10.6275(0.4596) \ddagger$ & $0.0048(0.0007) \dagger$ & $0.0692(0.0371) \ddagger$ & $0.1099(0.00002) \ddagger$ & $0.0042(0.0001)$ \\
\hline \multirow[t]{4}{*}{ FDA5iso } & total & $0.3949(0.0032)$ & $0.5905(0.0042)$ & $0.5789(0.0027)$ & $0.6493(0.0002) \ddagger$ & $0.6067(0.0021)$ \\
\hline & 1st stage & $0.4036(0.0060)$ & $0.5829(0.0056)$ & $0.5876(0.0075)$ & $0.6695(0.0005) \ddagger$ & $0.6181(0.0053)$ \\
\hline & 2nd stage & $0.3931(0.0068)$ & $0.5906(0.0062) \dagger$ & $0.5753(0.0039)$ & $0.6447(0.0001) \ddagger$ & $0.6043(0.0037)$ \\
\hline & 3rd stage & $0.3926(0.0061)$ & $0.5940(0.0056) \dagger$ & $0.5783(0.0034)$ & $0.6443(0.0002) \ddagger$ & $0.6037(0.0026)$ \\
\hline
\end{tabular}

effect for the problems whose PS are changeless over time. For FDA5iso, RIS has the best effect. FDA5iso is a three-dimensional problem and have a isolated PF, meaning that FDA5iso is a very difficult problem for prediction strategies including FPS, PPS and SPPS and the non-prediction algorithm, mcDMOA. So it is not strange that RIS is better than FPS, PPS, mcDMOA and SPPS. mcDMOA is best in the first stage on some test problems. That is because that FPS, PPS and SPPS are all prediction strategies, they need some time to accumulate experience to get their best results, but mcDMOA is not. The results of mcDMOA on the latter stages are worst than the first stage on some test problems, such as FDA1. The reason maybe that mcDMOA has a very bad effect for some environment changes, and the results on these environmental changes affect the mean values of the whole stages.
As shown in Table 2, the five strategies are compared for MHVD metric on the FDA test suite, the dMOP test suite, FDA5iso and dMOP2iso. mcDMOA is better than four other strategies and SPPS is the second best on most of test problems for MHVD values. There is a big difference for mcDMOA about MIGD and MHVD values. The reason maybe that mcDMOA has a very bad effect on some environmental changes. These bad results can influence greatly MIGD values, but not MHVD values according to the definitions of MIGD and MHVD.

\subsubsection{Experimental results of comparison experiment on F5-F10 and HE3-HE4}

As shown in Table 3, for the total stage, SPPS is slightly worse than FPS on three-dimensional problem F8, but better than RIS, FPS, PPS and mcDMOA for the other 
Table 2 Mean and Standard Deviation of MHVD values of five strategies on FDA, dMOP test suites and their variants, dMOP2iso and FDA5iso. $\ddagger$ and $\dagger$ indicate SPPS performs significantly better than and equivalently to the corresponding algorithm, respectively.

\begin{tabular}{|c|c|c|c|c|c|c|}
\hline Problems & Statistic & RIS & FPS & PPS & mcDMOA & SPPS \\
\hline \multirow[t]{4}{*}{ FDA1 } & total & $1.2328(0.0107) \ddagger$ & $0.0968(0.0105) \ddagger$ & $0.0948(0.0145) \ddagger$ & $0.6744(0.00005) \ddagger$ & $0.0422(0.0030)$ \\
\hline & 1st stage & $1.2145(0.0190) \ddagger$ & $0.3680(0.0522) \ddagger$ & $0.4192(0.0714) \ddagger$ & $0.0128(0.0002)$ & $0.1450(0.0150)$ \\
\hline & 2nd stage & $1.2353(0.0156) \ddagger$ & $0.0342(0.0025) \ddagger$ & $0.0222(0.0023) \ddagger$ & $0.8315(0.0001) \ddagger$ & $0.0178(0.0004)$ \\
\hline & 3rd stage & $1.2390(0.0128) \ddagger$ & $0.0305(0.0022) \ddagger$ & $0.0133(0.0002)$ & $0.8315(0.0001) \ddagger$ & $0.0178(0.0004)$ \\
\hline \multirow[t]{4}{*}{ FDA2 } & total & $0.0714(0.0013) \ddagger$ & $0.0320(0.0008)$ & $0.0325(0.0007) \dagger^{\prime}$ & $0.0178(0.00002)$ & $0.0324(0.0006)$ \\
\hline & 1st stage & $0.0719(0.0022) \ddagger$ & $0.0372(0.0041) \dagger$ & $0.0405(0.0041) \ddagger$ & $0.0201(0.00004)$ & $0.0365(0.0030)$ \\
\hline & 2nd stage & $0.0714(0.0021) \ddagger$ & $0.0306(0.0003) \ddagger$ & $0.0301(0.0003)$ & $0.0163(0.00004)$ & $0.0312(0.0002)$ \\
\hline & 3rd stage & $0.0711(0.0019) \ddagger$ & $0.0310(0.00004)$ & $0.0310(0.00005)$ & $0.0182(0.00003)$ & $0.0315(0.0001)$ \\
\hline \multirow[t]{4}{*}{ FDA3 } & total & $1.9361(0.0177) \ddagger$ & $0.7761(0.0183) \ddagger$ & $0.8420(0.0275) \ddagger$ & $0.5882(0.0038)$ & $0.6592(0.0056)$ \\
\hline & 1st stage & $1.9195(0.0482) \ddagger$ & $1.0479(0.0521) \ddagger$ & $1.2829(0.1490) \ddagger$ & $0.5128(0.0002)$ & $0.7401(0.0194)$ \\
\hline & 2nd stage & $1.9387(0.0253) \ddagger$ & $0.7167(0.0167) \ddagger$ & $0.7436(0.0185) \ddagger$ & $0.6001(0.0072)$ & $0.6428(0.0099)$ \\
\hline & 3rd stage & $1.9414(0.0296) \ddagger$ & $0.7064(0.0186) \ddagger$ & $0.7310(0.0269) \ddagger$ & $0.6122(0.0023)$ & $0.6373(0.0093)$ \\
\hline \multirow[t]{4}{*}{ FDA4 } & total & $1.3189(0.0178) \ddagger$ & $0.2449(0.0047) \ddagger$ & $0.2383(0.0051) \ddagger$ & $0.1046(0.0024)$ & $0.2166(0.0032)$ \\
\hline & 1st stage & $1.2517(0.0346) \ddagger$ & $0.3126(0.0137) \ddagger$ & $0.3133(0.0226) \ddagger$ & $0.1050(0.0072)$ & $0.2785(0.0141)$ \\
\hline & 2nd stage & $1.3242(0.0246) \ddagger$ & $0.2287(0.0065) \ddagger$ & $0.2224(0.0037) \ddagger$ & $0.1038(0.0041)$ & $0.2026(0.0028)$ \\
\hline & 3rd stage & $1.3454(0.0264) \ddagger$ & $0.2288(0.0071) \ddagger$ & $0.2185(0.0030) \ddagger$ & $0.1051(0.0037)$ & $0.2013(0.0024)$ \\
\hline \multirow[t]{4}{*}{ dMOP1 } & total & $1.1531(0.0182) \ddagger$ & $0.1501(0.0010) \ddagger$ & $0.1688(0.0311) \ddagger$ & $0.0395(0.0001)$ & $0.1463(0.0013)$ \\
\hline & 1st stage & $1.0885(0.0414) \ddagger$ & $0.1180(0.0048) \ddagger$ & $0.1715(0.0917) \ddagger$ & $0.0144(0.0003)$ & $0.0971(0.0070)$ \\
\hline & 2nd stage & $1.1718(0.0331) \ddagger$ & $0.1577(0.0002)$ & $0.1780(0.0370) \ddagger$ & $0.0321(0.00004)$ & $0.1583(0.0005)$ \\
\hline & 3rd stage & $1.1651(0.0282) \ddagger$ & $0.1576(0.0002)$ & $0.1583(0.0002) \dagger$ & $0.0589(0.00004)$ & $0.1577(0.0007)$ \\
\hline \multirow[t]{4}{*}{ dMOP2 } & total & $1.2672(0.0113) \ddagger$ & $0.2156(0.0131) \ddagger$ & $0.2190(0.0154) \ddagger$ & $0.0413(0.0001)$ & $0.1658(0.0021)$ \\
\hline & 1st stage & $1.1689(0.0209) \ddagger$ & $0.4303(0.0620) \ddagger$ & $0.4484(0.0766) \ddagger$ & $0.0195(0.0002)$ & $0.1922(0.0103)$ \\
\hline & 2nd stage & $1.2967(0.0214) \ddagger$ & $0.1656(0.0031) \ddagger$ & $0.1709(0.0024) \ddagger$ & $0.0328(0.0002)$ & $0.1597(0.0005)$ \\
\hline & 3rd stage & $1.2844(0.0206) \ddagger$ & $0.1636(0.0014) \ddagger$ & $0.1581(0.0002)$ & $0.0601(0.0002)$ & $0.1593(0.0004)$ \\
\hline \multirow[t]{4}{*}{ dMOP3 } & total & $1.2282(0.0095) \ddagger$ & $0.0972(0.0085) \ddagger$ & $0.0947(0.0147) \ddagger$ & $0.0169(0.0002)$ & $0.0434(0.0024)$ \\
\hline & 1st stage & $1.2046(0.0257) \ddagger$ & $0.3695(0.0440) \ddagger$ & $0.4193(0.0736) \ddagger$ & $0.0166(0.0004)$ & $0.1520(0.0125)$ \\
\hline & 2nd stage & $1.2317(0.0158) \ddagger$ & $0.0340(0.0017) \ddagger$ & $0.0219(0.0021) \ddagger$ & $0.0169(0.0002)$ & $0.0176(0.0004)$ \\
\hline & 3rd stage & $1.2359(0.0224) \ddagger$ & $0.0312(0.0018) \ddagger$ & $0.0133(0.0002)$ & $0.0169(0.0003)$ & $0.0175(0.0003)$ \\
\hline \multirow[t]{4}{*}{ dMOP2iso } & total & $1.3944(0.0048) \ddagger$ & $0.1938(0.0150) \ddagger$ & $0.2536(0.0252) \ddagger$ & $0.0388(0.00003)$ & $0.1756(0.0059)$ \\
\hline & 1st stage & $1.3337(0.0061) \ddagger$ & $0.3281(0.0785) \ddagger$ & $0.3331(0.0619) \ddagger$ & $0.0110(0.00003)$ & $0.2446(0.0309)$ \\
\hline & 2nd stage & $1.4088(0.0074) \ddagger$ & $0.1620(0.0020) \ddagger$ & $0.1866(0.0151) \ddagger$ & $0.0320(0.0001)$ & $0.1591(0.0005)$ \\
\hline & 3rd stage & $1.4089(0.0081) \ddagger$ & $0.1619(0.0023) \ddagger$ & $0.2827(0.0512) \ddagger$ & $0.0588(0.00003)$ & $0.1593(0.0006)$ \\
\hline \multirow[t]{4}{*}{ FDA5iso } & total & $1.1812(0.0374)$ & $1.8522(0.0076) \dagger$ & $1.8198(0.0054)$ & $2.0036(0.0007) \ddagger$ & $1.8749(0.0036)$ \\
\hline & 1st stage & $1.2205(0.0636)$ & $1.8754(0.0170)$ & $1.8679(0.0140)$ & $2.0176(0.0014) \ddagger$ & $1.9357(0.0090)$ \\
\hline & 2nd stage & $1.1802(0.0539)$ & $1.8439(0.0097) \dagger$ & $1.8066(0.0076)$ & $2.0218(0.0007) \ddagger$ & $1.8601(0.0049)$ \\
\hline & 3rd stage & $1.1635(0.0462)$ & $1.8495(0.0107)$ & $1.8103(0.0054)$ & $1.9788(0.0004) \ddagger$ & $1.8608(0.0038)$ \\
\hline
\end{tabular}

problems( $\mathrm{F}$ test suite). It indicates that the average performance of SPPS is better. At the early two stages, SPPS is better than RIS, FPS, PPS and mcDMOA for most of the problems. For the third stage, PPS is better than SPPS on two problems, F5 and F7. For HE3 and HE4, FPS is better than the other strategies. In conclusion, mcDMOA has a bad effect on these problems whose decision variables have difficult linkage. However, SPPS have the best results on these problems.

Explanations can also be used in Section 4.3.1. HE3 and HE4 are the problems whose PS are changeless over time and FPS includes memory strategy, so FPS is better significantly than RIS, PPS, mcDMOA and SPPS. F5-F7 are the problems with nonlinear correlation between design variables. For these problems, the prediction of PF are more difficult than FDA and dMOP test suites. PPS also needs to accumulate experience, and for the third stage, SPPS is slightly worse than PPS except F6. For F8, which is a three-dimensional problem, SPPS is better than the other strategies for most of the stages or all stages. F9-F10 are two more complicated problems than F5-F8. For F9, environmental changes are slight, but sometimes, the Pareto set can jump from one area to another. For F10, the shapes of two continual PFs are different. As shown in Table 3, SPPS is better than RIS, FPS, PPS and mcDMOA at almost all stages of F9-F10. This may be the fact that the adaptive population diversity maintenance mechanism plays an important role.

As shown in Table 4, the comparison results are almost the same with results of MIGD. MIGD and MHVD are the comprehensive metrics including convergence and distribution. So it is not strange about that. 
Table 3 Mean and Standard Deviation of MIGD values of five strategies on F5-F10 and HE3-HE4. $\ddagger$ and $\dagger$ indicate SPPS performs significantly better than and equivalently to the corresponding algorithm, respectively.

\begin{tabular}{|c|c|c|c|c|c|c|}
\hline Problems & Statistic & RIS & FPS & PPS & mcDMOA & SPPS \\
\hline \multirow[t]{4}{*}{ HE3 } & total & $0.1294(0.0018) \ddagger$ & $0.0912(0.00003)$ & $0.0920(0.0001) \dagger$ & $0.1366(0.00004) \ddagger$ & $0.0919(0.0001)$ \\
\hline & 1st stage & $0.1636(0.0037) \ddagger$ & $0.1091(0.0001)$ & $0.1110(0.0002) \dagger$ & $0.1598(0.0002) \ddagger$ & $0.1113(0.0002)$ \\
\hline & 2nd stage & $0.1216(0.0022) \ddagger$ & $0.0869(0.00004)$ & $0.0874(0.0001) \dagger$ & $0.1311(0.0001) \ddagger$ & $0.0873(0.0001)$ \\
\hline & 3rd stage & $0.1210(0.0034) \ddagger$ & $0.0869(0.0001)$ & $0.0874(0.0001) \dagger$ & $0.1310(0.00004) \ddagger$ & $0.0873(0.0001)$ \\
\hline \multirow[t]{4}{*}{$\mathrm{HE} 4$} & total & $0.3802(0.0035) \ddagger$ & $0.1223(0.0045)$ & $0.2092(0.0208) \ddagger$ & $0.1429(0.0008)$ & $0.1466(0.0023)$ \\
\hline & 1st stage & $0.4435(0.0123) \ddagger$ & $0.1755(0.0136)$ & $0.2755(0.0380) \ddagger$ & $0.1918(0.0013)$ & $0.1951(0.0110)$ \\
\hline & 2nd stage & $0.3651(0.0080) \ddagger$ & $0.1102(0.0045)$ & $0.2004(0.0296) \ddagger$ & $0.1309(0.0007)$ & $0.1348(0.0013)$ \\
\hline & 3rd stage & $0.3653(0.0089) \ddagger$ & $0.1092(0.0020)$ & $0.1866(0.0218) \ddagger$ & $0.1318(0.0011)$ & $0.1354(0.0018)$ \\
\hline \multirow[t]{4}{*}{ F5 } & total & $1.1439(0.0418) \ddagger$ & $0.1852(0.0819) \ddagger$ & $0.2323(0.0773) \ddagger$ & $0.3593(0.0053) \ddagger$ & $0.0350(0.0079)$ \\
\hline & 1st stage & $1.1844(0.0677) \ddagger$ & $0.5886(0.4113) \ddagger$ & $1.0473(0.3624) \ddagger$ & $0.3796(0.0134) \ddagger$ & $0.1027(0.0400)$ \\
\hline & 2nd stage & $1.1344(0.0405) \ddagger$ & $0.1088(0.0289) \ddagger$ & $0.0664(0.0270) \ddagger$ & $0.3664(0.0052) \ddagger$ & $0.0189(0.0015)$ \\
\hline & 3rd stage & $1.1341(0.0602) \ddagger$ & $0.0746(0.0253) \ddagger$ & $0.0169(0.0013)$ & $0.3427(0.0056) \ddagger$ & $0.0189(0.0011)$ \\
\hline \multirow[t]{4}{*}{ F6 } & total & $0.5399(0.0122) \ddagger$ & $0.0548(0.0168) \ddagger$ & $0.0751(0.0424) \ddagger$ & $0.3073(0.0039) \ddagger$ & $0.0206(0.0023)$ \\
\hline & 1st stage & $0.6958(0.0392) \ddagger$ & $0.1291(0.0774) \ddagger$ & $0.3084(0.2049) \ddagger$ & $0.3165(0.0054) \ddagger$ & $0.0445(0.0120)$ \\
\hline & 2nd stage & $0.5103(0.0190) \ddagger$ & $0.0404(0.0082) \ddagger$ & $0.0269(0.0092) \ddagger$ & $0.3107(0.0045) \ddagger$ & $0.0149(0.0003)$ \\
\hline & 3rd stage & $0.4956(0.0167) \ddagger$ & $0.0352(0.0050) \ddagger$ & $0.0143(0.0005) \dagger$ & $0.2995(0.0053) \ddagger$ & $0.0140(0.0004)$ \\
\hline \multirow[t]{4}{*}{ F7 } & total & $0.6165(0.0153) \ddagger$ & $0.1273(0.0234) \ddagger$ & $0.1006(0.0402) \ddagger$ & $0.3068(0.0040) \ddagger$ & $0.0203(0.0030)$ \\
\hline & 1st stage & $0.6764(0.0335) \ddagger$ & $0.3499(0.1031) \ddagger$ & $0.4575(0.2036) \ddagger$ & $0.3001(0.0099) \ddagger$ & $0.0452(0.0161)$ \\
\hline & 2nd stage & $0.6009(0.0192) \ddagger$ & $0.0879(0.0255) \ddagger$ & $0.0208(0.0042) \ddagger$ & $0.3135(0.0031) \ddagger$ & $0.0143(0.0003)$ \\
\hline & 3rd stage & $0.6037(0.0255) \ddagger$ & $0.0642(0.0247) \ddagger$ & $0.0133(0.0005)$ & $0.3032(0.0068) \ddagger$ & $0.0144(0.0003)$ \\
\hline \multirow[t]{4}{*}{ F8 } & total & $0.9083(0.0248) \ddagger$ & $0.1418(0.0036)$ & $0.1455(0.0046) \ddagger$ & $0.3245(0.0085) \ddagger$ & $0.1423(0.0048)$ \\
\hline & 1st stage & $0.7666(0.0411) \ddagger$ & $0.1944(0.0164)$ & $0.2106(0.0237) \dagger$ & $0.3752(0.0080) \ddagger$ & $0.2127(0.0197)$ \\
\hline & 2nd stage & $0.9473(0.0444) \ddagger$ & $0.1313(0.0029) \ddagger$ & $0.1335(0.0020) \ddagger$ & $0.3294(0.0108) \ddagger$ & $0.1258(0.0029)$ \\
\hline & 3rd stage & $0.9366(0.0264) \ddagger$ & $0.1309(0.0017) \dagger$ & $0.1301(0.0025) \ddagger$ & $0.2955(0.0095) \ddagger$ & $0.1254(0.0037)$ \\
\hline \multirow[t]{4}{*}{ F9 } & total & $1.1923(0.0325) \ddagger$ & $0.3542(0.0675) \ddagger$ & $0.6186(0.1948) \ddagger$ & $0.3602(0.0109) \ddagger$ & $0.1078(0.0189)$ \\
\hline & 1st stage & $1.2308(0.1003) \ddagger$ & $0.9770(0.1926) \ddagger$ & $2.5294(0.9519) \ddagger$ & $0.4298(0.0265) \ddagger$ & $0.3019(0.0777)$ \\
\hline & 2nd stage & $1.1787(0.0672) \ddagger$ & $0.2203(0.0749) \ddagger$ & $0.2632(0.0961) \ddagger$ & $0.3667(0.0096) \ddagger$ & $0.0645(0.0222)$ \\
\hline & 3rd stage & $1.1875(0.0485) \ddagger$ & $0.2012(0.0849) \ddagger$ & $0.0819(0.0160) \ddagger$ & $0.3207(0.0084) \ddagger$ & $0.0590(0.0120)$ \\
\hline \multirow[t]{4}{*}{ F10 } & total & $1.0691(0.0472) \ddagger$ & $0.4280(0.0531) \ddagger$ & $0.5097(0.0998) \ddagger$ & $0.1557(0.0026) \ddagger$ & $0.0720(0.0205)$ \\
\hline & 1st stage & $1.1510(0.0772) \ddagger$ & $0.6341(0.1203) \ddagger$ & $1.5974(0.4401) \ddagger$ & $0.1667(0.0087)$ & $0.2386(0.1035)$ \\
\hline & 2nd stage & $1.0608(0.0491) \ddagger$ & $0.4188(0.0575) \ddagger$ & $0.3004(0.0877) \ddagger$ & $0.1533(0.0042) \ddagger$ & $0.0332(0.0033)$ \\
\hline & 3rd stage & $1.0385(0.0750) \ddagger$ & $0.3499(0.0666) \ddagger$ & $0.2150(0.0439) \ddagger$ & $0.1529(0.0034) \ddagger$ & $0.0318(0.0038)$ \\
\hline
\end{tabular}

\subsection{Distribution diagram of final population}

For a more intuitive comparison, we selected FDA1, dMOP2, F6 and F10 to draw the final population distribution of the five strategies. It is the test problem of fixed PS in Fig. 7, selecting six moments to observe results. Eight moments are selected in the other figures. It can be seen from Fig. 7 and Fig. 8 that the experimental results are the same as those in Tables 1 and 2 . In the early stages, SPPS has better convergence and distribution, which shows that SPPS can better respond to environmental changes. In the later stage, the effect of PPS and SPPS is the best, and their points are very close to PF. mcDMOA has good convergence on most of time steps, but has bad convergence on some time steps, such as $t=70$ on FDA1 and $t=5$ on dMOP2. It maybe that the situation of mcDMOA causes the big difference of MIGD values and MHVD values. From Fig. 9 and Fig. 10, it can be seen that the experimental results are substantially the same as those in Tables 3 and 4. The problem in Fig. 9 is F6, which is a complicated problem. Figure 10 shows a more complex prob- lem, F10. It can be seen that SPPS works much better for complex problems than the other strategies.

\section{Conclusions and future work}

This paper has presented a prediction strategy based on special points. The non-dominated set predicted by feed-forward center points is the body of the predicted population. The special point set predicted by prediction model is regarded as the guidance individuals, which makes the strategy track the PF more accurately and respond to the environment faster. The adaptive diversity maintenance strategy can adaptively introduce random individuals of different numbers according to the degree of difficulty of the problem to keep the diversity of the population.

We selected the FDA and dMOP test suites, FDA5iso and dMOP2iso, a total of nine test problems whose decision variables were linearly related. In addition, F5F10 and HE3-HE4 were selected and their decision variables are nonlinear correlation. It can be seen that SPPS 
Table 4 Mean and Standard Deviation of MHVD values of five strategies on F5-F10 and HE3-HE4. $\ddagger$ and $\dagger$ indicate SPPS performs significantly better than and equivalently to the corresponding algorithm, respectively.

\begin{tabular}{|c|c|c|c|c|c|c|}
\hline Problems & Statistic & RIS & FPS & PPS & mcDMOA & SPPS \\
\hline \multirow[t]{4}{*}{ HE3 } & total & $0.3358(0.0062) \ddagger$ & $0.1868(0.0001)$ & $0.1918(0.0004) \ddagger$ & $0.2873(0.0001)$ & $0.1901(0.0006)$ \\
\hline & 1st stage & $0.4279(0.0118) \ddagger$ & $0.2293(0.0005)$ & $0.2392(0.0011) \ddagger$ & $0.3580(0.0005)$ & $0.2370(0.0010)$ \\
\hline & 2nd stage & $0.3147(0.0082) \ddagger$ & $0.1767(0.0002)$ & $0.1804(0.0007) \ddagger$ & $0.2752(0.0002)$ & $0.1792(0.0008)$ \\
\hline & 3rd stage & $0.3133(0.0115) \ddagger$ & $0.1767(0.0002)$ & $0.1806(0.0007) \ddagger$ & $0.2659(0.0001)$ & $0.1788(0.0006)$ \\
\hline \multirow[t]{4}{*}{$\mathrm{HE} 4$} & total & $1.0840(0.0089) \ddagger$ & $0.2955(0.0222)$ & $0.6290(0.0540) \ddagger$ & $0.3388(0.0014)$ & $0.3968(0.0102)$ \\
\hline & 1st stage & $1.1889(0.0207) \ddagger$ & $0.4896(0.0483)$ & $0.7746(0.0832) \ddagger$ & $0.5069(0.0037)$ & $0.5689(0.0316)$ \\
\hline & 2nd stage & $1.0597(0.0164) \ddagger$ & $0.2587(0.0259)$ & $0.6127(0.0819) \ddagger$ & $0.3031(0.0017)$ & $0.3619(0.0126)$ \\
\hline & 3rd stage & $1.0585(0.0176) \ddagger$ & $0.2401(0.0082)$ & $0.5762(0.0670) \ddagger$ & $0.2947(0.0018)$ & $0.3499(0.0083)$ \\
\hline \multirow[t]{4}{*}{ F5 } & total & $1.3849(0.0142) \ddagger$ & $0.4745(0.0707) \ddagger$ & $0.4845(0.0535) \ddagger$ & $0.5234(0.0158)$ & $0.2821(0.0116)$ \\
\hline & 1st stage & $1.5641(0.0325) \ddagger$ & $0.9525(0.2942) \ddagger$ & $1.3391(0.2164) \ddagger$ & $0.7280(0.0212)$ & $0.4372(0.0566)$ \\
\hline & 2nd stage & $1.3441(0.0169) \ddagger$ & $0.3951(0.0542) \ddagger$ & $0.3148(0.0415) \ddagger$ & $0.5205(0.0209)$ & $0.2461(0.0037)$ \\
\hline & 3rd stage & $1.3406(0.0281) \ddagger$ & $0.3269(0.0438) \ddagger$ & $0.2483(0.0011) \ddagger$ & $0.4292(0.0120)$ & $0.2445(0.0021)$ \\
\hline \multirow[t]{4}{*}{ F6 } & total & $0.9995(0.0153) \ddagger$ & $0.3050(0.0325) \ddagger$ & $0.3436(0.0487) \ddagger$ & $0.4156(0.0141)$ & $0.2668(0.0056)$ \\
\hline & 1st stage & $1.3182(0.0408) \ddagger$ & $0.4923(0.1479) \ddagger$ & $0.7177(0.2266) \ddagger$ & $0.6068(0.0146)$ & $0.3507(0.0299)$ \\
\hline & 2nd stage & $0.9273(0.0209) \ddagger$ & $0.2646(0.0201) \ddagger$ & $0.2626(0.0140) \ddagger$ & $0.3972(0.0199)$ & $0.2466(0.0008)$ \\
\hline & 3rd stage & $0.9204(0.0210) \ddagger$ & $0.2565(0.0086) \ddagger$ & $0.2468(0.0011)$ & $0.3432(0.0117)$ & $0.2470(0.0008)$ \\
\hline \multirow[t]{4}{*}{ F7 } & total & $1.0988(0.0152) \ddagger$ & $0.4448(0.0439) \ddagger$ & $0.3625(0.0288) \ddagger$ & $0.3830(0.0094)$ & $0.2642(0.0065)$ \\
\hline & 1st stage & $1.3190(0.0388) \ddagger$ & $0.8952(0.1753) \ddagger$ & $0.8413(0.1414) \ddagger$ & $0.5016(0.0274)$ & $0.3440(0.0343)$ \\
\hline & 2nd stage & $1.0465(0.0274) \ddagger$ & $0.3599(0.0516) \ddagger$ & $0.2509(0.0045) \ddagger$ & $0.3897(0.0077)$ & $0.2454(0.0005)$ \\
\hline & 3rd stage & $1.0464(0.0218) \ddagger$ & $0.3157(0.0452) \ddagger$ & $0.2467(0.0013) \ddagger$ & $0.3201(0.0124)$ & $0.2450(0.0007)$ \\
\hline \multirow[t]{4}{*}{ F8 } & total & $2.6165(0.0143) \ddagger$ & $0.2569(0.0117)$ & $0.3563(0.0353) \ddagger$ & $0.2296(0.0012)$ & $0.2877(0.0073)$ \\
\hline & 1st stage & $2.5636(0.0449) \ddagger$ & $0.4572(0.0590)$ & $0.7790(0.1694) \ddagger$ & $0.2359(0.0043)$ & $0.4734(0.0369)$ \\
\hline & 2nd stage & $2.6324(0.0259) \ddagger$ & $0.2107(0.0068)$ & $0.2689(0.0142) \ddagger$ & $0.2282(0.0012)$ & $0.2432(0.0084)$ \\
\hline & 3rd stage & $2.6258(0.0323) \ddagger$ & $0.2080(0.0055)$ & $0.2430(0.0098) \dagger$ & $0.2281(0.0013)$ & $0.2440(0.0078)$ \\
\hline \multirow[t]{4}{*}{ F9 } & total & $1.3930(0.0140) \ddagger$ & $0.6393(0.0872) \ddagger$ & $0.6481(0.0728) \ddagger$ & $0.4215(0.0201) \ddagger$ & $0.3444(0.0121)$ \\
\hline & 1st stage & $1.5966(0.0330) \ddagger$ & $1.2334(0.1652) \ddagger$ & $1.6530(0.2620) \ddagger$ & $0.7156(0.0110) \ddagger$ & $0.6291(0.0428)$ \\
\hline & 2nd stage & $1.3371(0.0155) \ddagger$ & $0.5259(0.1036) \ddagger$ & $0.5175(0.1047) \ddagger$ & $0.3977(0.0250) \ddagger$ & $0.2789(0.0212)$ \\
\hline & 3rd stage & $1.3523(0.0308) \ddagger$ & $0.4705(0.1276) \ddagger$ & $0.3014(0.0261) \ddagger$ & $0.3055(0.0209) \ddagger$ & $0.2746(0.0152)$ \\
\hline \multirow[t]{4}{*}{ F10 } & total & $1.3534(0.0188) \ddagger$ & $0.8905(0.0706) \ddagger$ & $0.7476(0.0559) \ddagger$ & $0.5291(0.0227) \ddagger$ & $0.3352(0.0252)$ \\
\hline & 1st stage & $1.5587(0.0333) \ddagger$ & $1.2692(0.1157) \ddagger$ & $1.5369(0.0976) \ddagger$ & $0.8480(0.0462) \ddagger$ & $0.6440(0.1245)$ \\
\hline & 2nd stage & $1.3022(0.0223) \ddagger$ & $0.8541(0.0927) \ddagger$ & $0.6028(0.0932) \ddagger$ & $0.5129(0.0235) \ddagger$ & $0.2633(0.0046)$ \\
\hline & 3rd stage & $1.3071(0.0290) \ddagger$ & $0.7471(0.1053) \ddagger$ & $0.5175(0.0713) \ddagger$ & $0.3937(0.0166) \ddagger$ & $0.2604(0.0036)$ \\
\hline
\end{tabular}

was better than RIS, FPS and PPS at total, the first and second stages. At the third stage, SPPS was better than PPS for most of the problems, but also slightly worse than PPS for other problems. It is because PPS accumulates enough experience to make it better than SPPS at the third stage. It is a disadvantage of SPPS. This will be the focus of our future work. Moreover, we find that memory strategy(included in FPS) has a good effect on the problems whose PS are changeless over time. So mixing SPPS and memory strategy is also an our future work. SPPS is better than mcDMOA on the problems whose decision variables are nonlinearly related. However, SPPS is worse than mcDMOA on some problems whose decision variables are linearly related. The reason maybe the function of local exploitation in mcDMOA. We also try to add some kind of local exploitation to SPPS. Besides, how to better use these special points to track PF or PS, so as to better reflect the advantage of these special points, is another important work for future study.
Acknowledgements The authors wish to thank the support of the National Natural Science Foundation of China (Grant No. 61502408, 61673331), the Education Department Major Project of Hunan Province (Grant No. 17A212), CERNET Innovation Project (Grant No. NGII20150302), The MOE Key Laboratory of Intelligent Computing and Information Processing, the Science and Technology Plan Project of Hunan Province (Grant No. 2016TP1020), the Provinces and Cities Joint Foundation Project (Grant No. 2017JJ4001).

\section{Compliance with Ethical Standards:}

Funding: This study was funded by National Nature Foundation of China (Grant No. 61379062, 61403326, 61502408, 61673331), the Hunan Province Natural Science Foundation (Grant No. 14JJ2072), CERNET Innovation Project (Grant No. NGII20150302).

Conflict of Interest: The authors declare that they have no conflict of interest.

Ethical approval: This article does not contain any studies with human participants or animals performed by any of authors. 

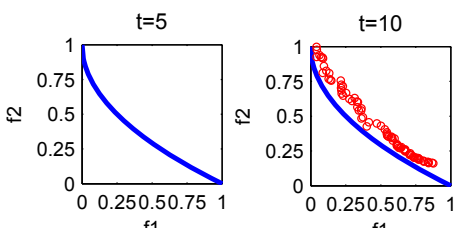

f1

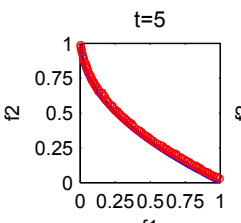

f1
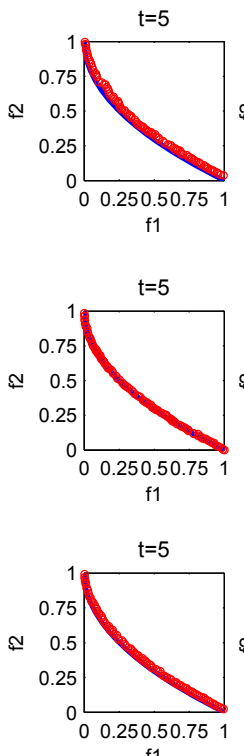

f1

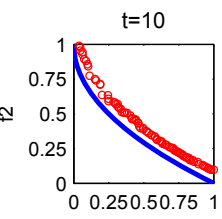

f1
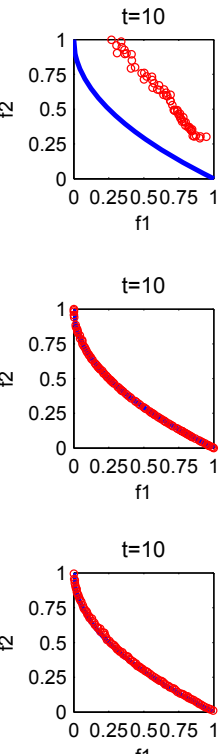

f1

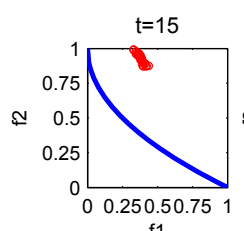

$\mathrm{f} 1$
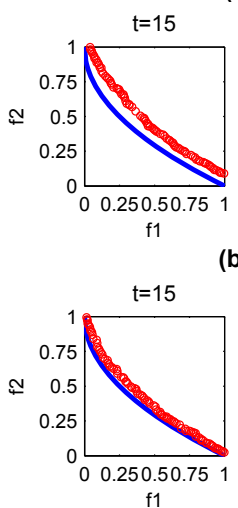

f1

(c) PPS

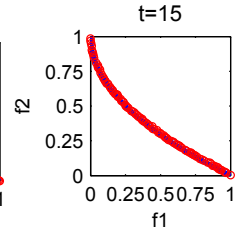

(d)

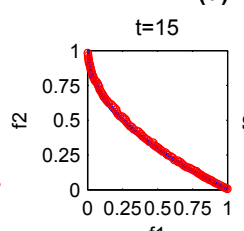

f1

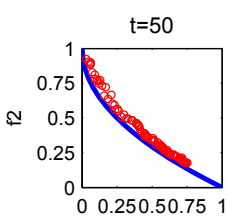

(a) RIS

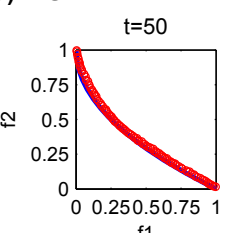

(b) FPS
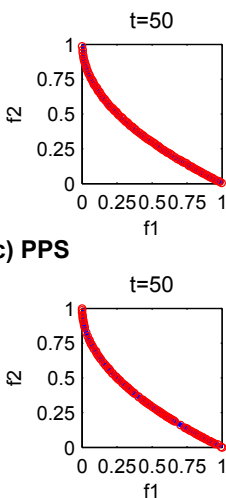

d) $\mathrm{mcDMOA}$

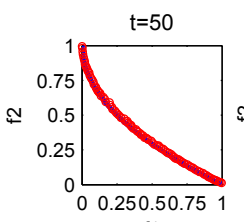

(e) SPPS
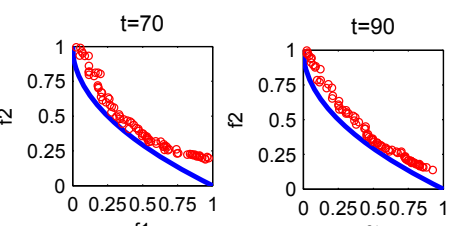

f1
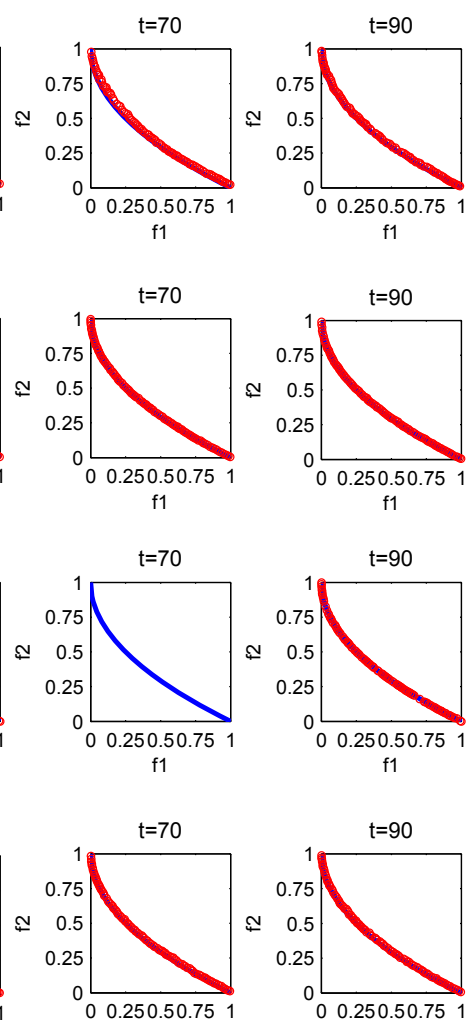

$\mathrm{f} 1$

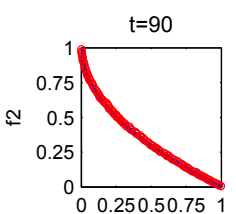

f1

Fig. 7 Final population distribution of the five strategies on FDA1.

Informed consent: Informed consent was obtained from all individual participants included in the study.

\section{References}

1. Jiang S, Yang S. Evolutionary Dynamic Multiobjective Optimization: Benchmarks and Algorithm Comparisons[J]. IEEE Transactions on Cybernetics, 2016, $\operatorname{PP}(99): 1-14$.

2. Deb K, Agrawal S, Pratap A, et al. A fast elitist nondominated sorting genetic algorithm for multi-objective optimization: NSGA-II[C] //International Conference on Parallel Problem Solving From Nature. Springer Berlin Heidelberg, 2000: 849-858.

3. Ziztler E. Laumanns. $M$ and Thiele, L.(2001). SPEA 2: Improving the Strength Pareto Evolutionary algorithm[R]. Technical report 103, Computer Engineering and Networks Laboratory, ETH, Zurich, Switzerland. Prix de leau, redevance prleve sur lusager.

4. Abello M B, Bui L T, Michalewicz Z. An adaptive approach for solving dynamic scheduling with time-varying number of tasksPart II[C]//2011 IEEE Congress of Evolutionary Computation (CEC). IEEE, 2011: 1711-1718.

5. Zhang Z. Multiobjective optimization immune algorithm in dynamic environments and its application to greenhouse control[J]. Applied Soft Computing, 2008, 8(2): 959-971.

6. Martins F V C, Carrano E G, Wanner E F, et al. A dynamic multiobjective hybrid approach for designing wireless sensor networks[C]//2009 IEEE Congress on Evolutionary Computation. IEEE, 2009: 1145-1152.

7. Kim K, McKay R I, Moon B R. Multiobjective evolutionary algorithms for dynamic social network clustering $[\mathrm{C}] / /$ Proceedings of the 12 th annual conference on Genetic and evolutionary computation. ACM, 2010: 11791186.

8. Rabil B S, Sabourin R, Granger E. Watermarking Stack of Grayscale Face Images as Dynamic Multi-Objective Optimization Problem[C]//MDA. 2011: 63-77.

9. Zeng S, Chen S, Zhao J, et al. Dynamic constrained multi-objective model for solving constrained optimization problem[C]//2011 IEEE Congress of Evolutionary Computation (CEC). IEEE, 2011: 2041-2046.

10. Branke J. Evolutionary optimization in dynamic environments[M]. Springer Science \& Business Media, 2012. 


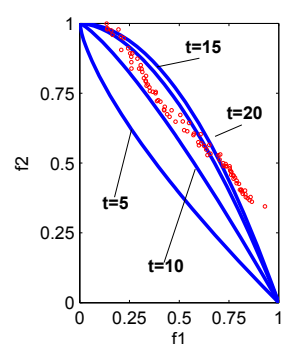

(a) RIS

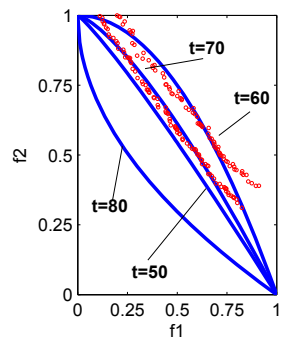

(a) RIS

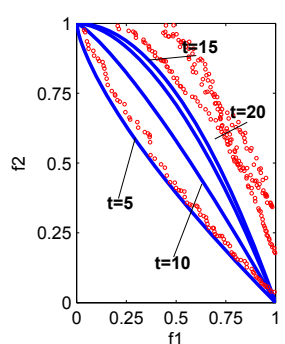

(b) FPS

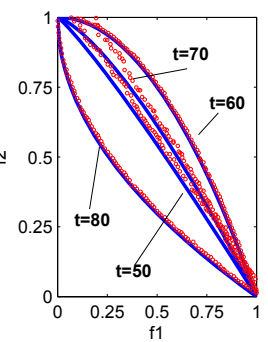

(b) FPS

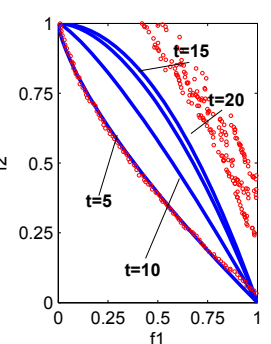

(c) PPS

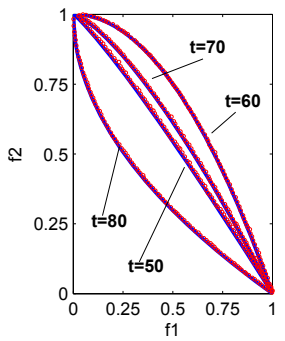

(c) PPS

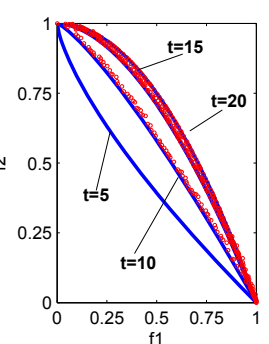

(d) $\mathrm{mcDMOA}$

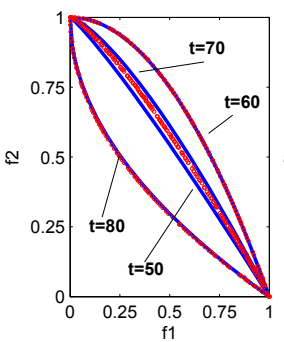

(d) $\mathrm{mcDMOA}$

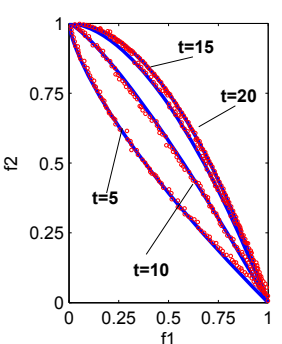

(e) SPPS

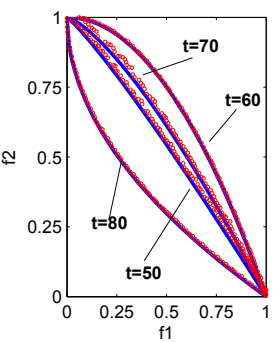

(e) SPPS

Fig. 8 Final population distribution of the five strategies on dMOP2.

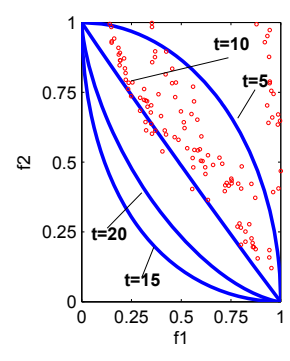

(a) RIS

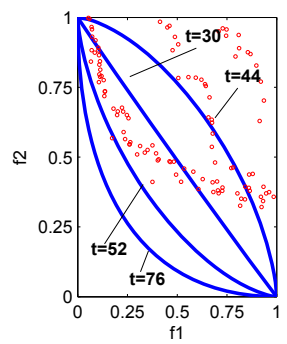

(a) RIS

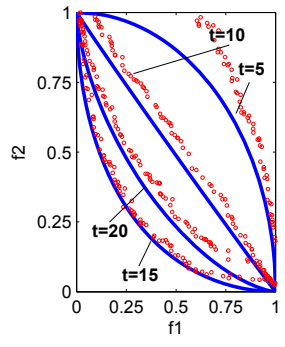

(b) FPS

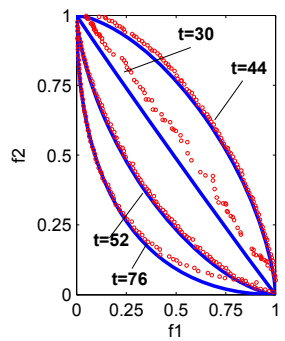

(b) FPS

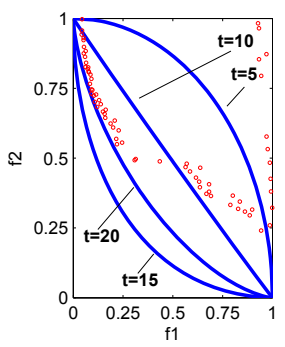

(c) PPS

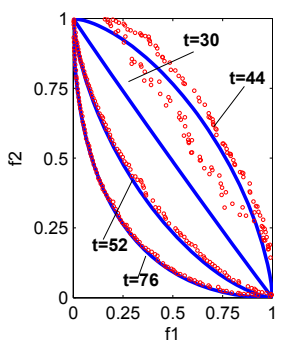

(c) PPS
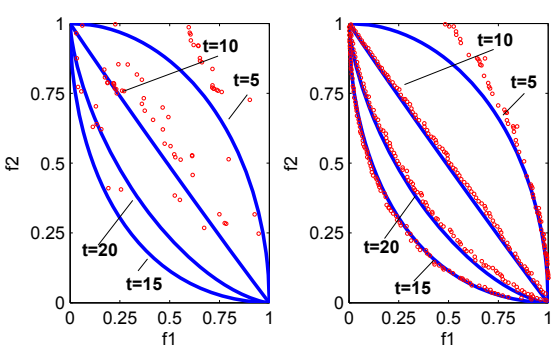

(d) $\mathrm{mcDMOA}$

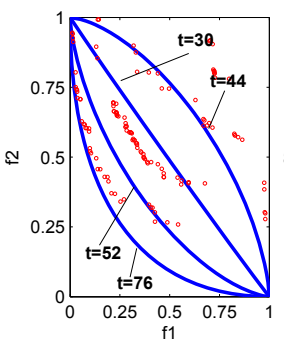

(d) $\mathrm{mcDMOA}$

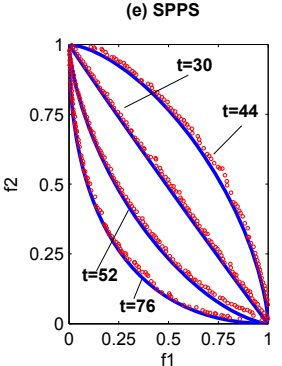

(e) SPPS

Fig. 9 Final population distribution of the five strategies on F6

11. Goh C K, Tan K C. Evolutionary multi-objective optimization in uncertain environments[J]. Issues and Algorithms, Studies in Computational Intelligence, 2009, 186.

12. Jin Y, Branke J. Evolutionary optimization in uncertain environments-a survey[J]. IEEE Transactions on evolutionary computation, 2005, 9(3): 303-317.

13. Nguyen T T, Yang S, Branke J. Evolutionary dynamic optimization: A survey of the state of the art[J]. Swarm and Evolutionary Computation, 2012, 6: 1-24.

14. Chun'an L, Yuping W. Multiobjective evolutionary algorithm for dynamic nonlinear constrained optimization problems[J]. Journal of Systems Engineering and Electronics, 2009, 20(1): 204-210.
15. Liu C, Wang Y. New evolutionary algorithm for dynamic multiobjective optimization problems $[\mathrm{C}] / /$ International Conference on Natural Computation. Springer Berlin Heidelberg, 2006: 889-892

16. Greeff M, Engelbrecht A P. Solving dynamic multiobjective problems with vector evaluated particle swarm optimisation[C]//2008 IEEE Congress on Evolutionary Computation (IEEE World Congress on Computational Intelligence). IEEE, 2008: 2917-2924.

17. Helbig M, Engelbrecht A P. Analyses of guide update approaches for vector evaluated particle swarm optimisation on dynamic multi-objective optimisation problems $[\mathrm{C}] / / 2012$ IEEE Congress on Evolutionary Compu- 


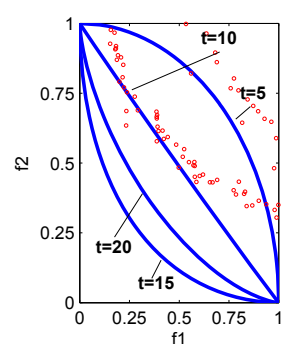

(a) RIS

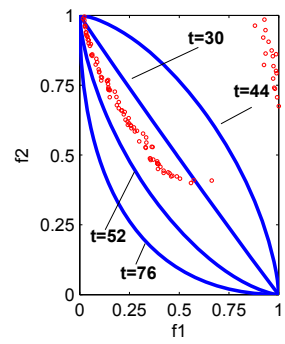

(a) RIS

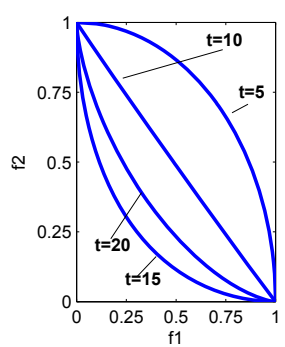

(b) FPS

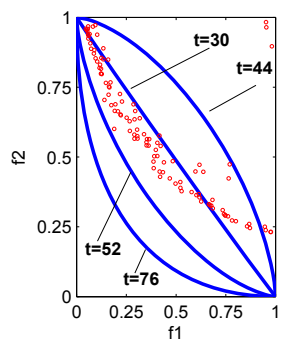

(b) FPS

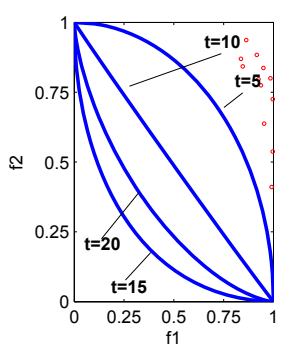

(c) PPS

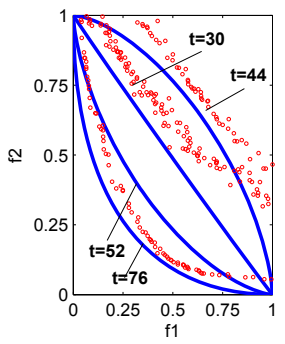

(c) PPS

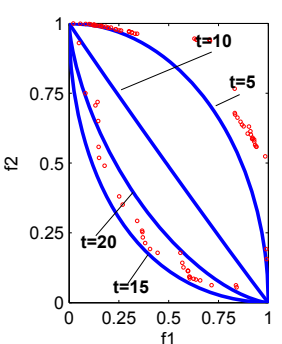

(d) McDMOA

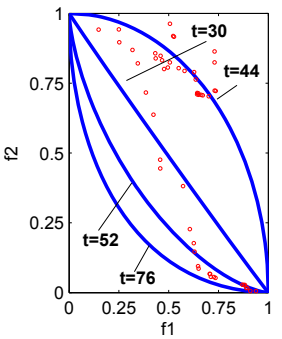

(d) $\mathrm{mcDMOA}$

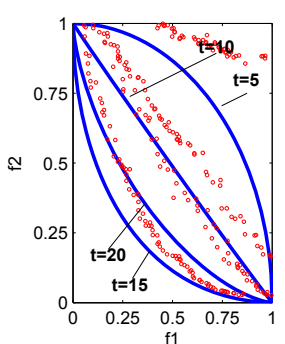

(e) SPPS

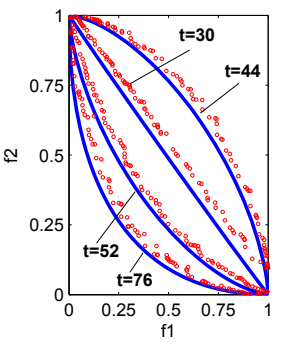

(e) SPPS

Fig. 10 Final population distribution of the five strategies on F10

tation. IEEE, 2012: 1-8.

18. Coello C A C, Pulido G T, Lechuga M S. Handling multiple objectives with particle swarm optimization $[\mathrm{J}]$. IEEE Transactions on evolutionary computation, 2004, 8(3): 256-279.

19. Vinek E, Beran P P, Schikuta E. A dynamic multiobjective optimization framework for selecting distributed deployments in a heterogeneous environment $[\mathrm{J}]$. Procedia Computer Science, 2011, 4: 166-175.

20. Isaacs A, Puttige V, Ray $\mathrm{T}$, et al. Development of a memetic algorithm for dynamic multi-objective optimization and its applications for online neural network modeling of UAVs[C]//2008 IEEE International Joint Conference on Neural Networks (IEEE World Congress on Computational Intelligence). IEEE, 2008: 548-554.

21. Guan S U, Chen Q, Mo W. Evolving dynamic multiobjective optimization problems with objective replacement[J]. Artificial Intelligence Review, 2005, 23(3): 267293.

22. Zhou A, Jin Y, Zhang Q, et al. Prediction-based population re-initialization for evolutionary dynamic multiobjective optimization $[\mathrm{C}] / /$ International Conference on Evolutionary Multi-Criterion Optimization. Springer Berlin Heidelberg, 2007: 832-846.

23. Ma Y, Liu R, Shang R. A hybrid dynamic multi-objective immune optimization algorithm using prediction strategy and improved differential evolution crossover operator[C]//International Conference on Neural Information Processing. Springer Berlin Heidelberg, 2011: 435-444.

24. Liu R, Zhang W, Jiao L, et al. A sphere-dominance based preference immune-inspired algorithm for dynamic multiobjective optimization[C]//Proceedings of the 12th annual conference on Genetic and evolutionary computation. ACM, 2010: 423-430.

25. Wei J, Zhang M. Simplex model based evolutionary algorithm for dynamic multi-objective optimization $[\mathrm{C}] / /$ Australasian Joint Conference on Artificial Intelligence. Springer Berlin Heidelberg, 2011: 372-381.

26. Aragn V S, Esquivel S C, Coello Coello C. Evolutionary multiobjetive optimization in non-stationary envi-
ronments[J]. Journal of Computer Science \& Technology, 2005, 5 .

27. Azevedo C R B, Arajo A F R. Generalized immigration schemes for dynamic evolutionary multiobjective optimization[C]//2011 IEEE Congress of Evolutionary Computation (CEC). IEEE, 2011: 2033-2040.

28. Cmara M, Ortega J, de Toro F. Approaching dynamic multi-objective optimization problems by using parallel evolutionary algorithms[M]//Advances in MultiObjective Nature Inspired Computing. Springer Berlin Heidelberg, 2010: 63-86.

29. Cmara M, Ortega J, de Toro F. A single front genetic algorithm for parallel multi-objective optimization in dynamic environments[J]. Neurocomputing, 2009, 72(16): 3570-3579.

30. Qian S, Ye Y, Jiang B, et al. A Micro-cloning dynamic multiobjective algorithm with an adaptive change reaction strategy[J]. Soft Computing, 2017,(21):13:37813801.

31. Jin Y, Sendhoff B. Constructing Dynamic Optimization Test Problems Using the Multi-objective Optimization Concept $[\mathrm{C}] / /$ Applications of Evolutionary Computing, EvoWorkshops 2004: EvoBIO, EvoCOMNET, EvoHOT, EvoIASP, EvoMUSART, and EvoSTOC, Coimbra, Portugal, April 5-7, 2004, Proceedings. 2004:525-536.

32. Muruganantham A, Tan K C, Vadakkepat P. Evolutionary Dynamic Multiobjective Optimization Via Kalman Filter Prediction $[\mathrm{J}]$. IEEE Transactions on Cybernetics, 2016, 46(12):2862-2873.

33. Nguyen T T, Yang S, Branke J. Evolutionary dynamic optimization: A survey of the state of the art[J]. Swarm and Evolutionary Computation, 2012, 6: 1-24.

34. Deb K, Karthik S. Dynamic multi-objective optimization and decision-making using modified NSGAII: a case study on hydro-thermal power scheduling[C]//International Conference on Evolutionary MultiCriterion Optimization. Springer Berlin Heidelberg, 2007: 803-817. 
35. Coello C C, Lamont G B, Van Veldhuizen D A. Evolutionary algorithms for solving multi-objective problems[M]. Springer Science \& Business Media, 2007.

36. Zhou A, Jin Y, Zhang Q, et al. Prediction-based population re-initialization for evolutionary dynamic multiobjective optimization[C]//International Conference on Evolutionary Multi-Criterion Optimization. Springer Berlin Heidelberg, 2007: 832-846.

37. Hatzakis I, Wallace D. Topology of anticipatory populations for evolutionary dynamic multi-objective optimization[C]//11th AIAA/ISSMO Multidisciplinary Analysis and Optimization Conference. 2006: 7071.

38. Hatzakis I, Wallace D. Dynamic multi-objective optimization with evolutionary algorithms: a forward-looking approach $[\mathrm{C}] / /$ Proceedings of the 8 th annual conference on Genetic and evolutionary computation. ACM, 2006: 1201-1208.

39. Zhou A, Jin Y, Zhang Q. A population prediction strategy for evolutionary dynamic multiobjective optimization[J]. IEEE transactions on cybernetics, 2014, 44(1): 40-53.

40. Wu Y, Jin Y, Liu X. A directed search strategy for evolutionary dynamic multiobjective optimization[J]. Soft Computing, 2015, 19(11): 3221-3235.

41. Qian S, Ye Y, Jiang B, et al. A Micro-cloning dynamic multiobjective algorithm with an adaptive change reaction strategy[J]. Soft Computing, 2016:1-21.

42. Wu Y, Liu X X, Chi C Z. Predictive multiobjective genetic algorithm for dynamic multiobjective optimization problems[J]. Control and Decision, 2013, 28(5): 677-682.

43. Zheng J H, Peng Z, Zou J, et al. A prediction strategy based on guide-individual for dynamic multi-objective optimization[J]. 2015.

44. Zhang X, Tian Y, Jin Y. A knee point-driven evolutionary algorithm for many-objective optimization[J]. IEEE Transactions on Evolutionary Computation, 2015, 19(6): 761-776.

45. Das I. On characterizing the knee of the Pareto curve based on normal-boundary intersection $[\mathrm{J}]$. Structural Optimization, 1999, 18(2-3): 107-115.

46. Branke J, Deb K, Dierolf H, et al. Finding knees in multiobjective optimization $[\mathrm{C}] / /$ International Conference on Parallel Problem Solving from Nature. Springer Berlin Heidelberg, 2004: 722-731.

47. Deb K, Gupta S. Understanding knee points in bicriteria problems and their implications as preferred solution principles[J]. Engineering optimization, 2011, 43(11): 1175-1204.

48. Peng Z, Zheng J, Zou J, et al. Novel prediction and memory strategies for dynamic multiobjective optimization $[\mathrm{J}]$. Soft Computing, 2015, 19(9): 2633-2653.

49. Peng Z, Zheng J, Zou J. A population diversity maintaining strategy based on dynamic environment evolutionary model for dynamic multiobjective optimization[C]//2014 IEEE Congress on Evolutionary Computation (CEC). IEEE, 2014: 274-281.

50. Farina M, Deb K, Amato P. Dynamic multiobjective optimization problems: test cases, approximations, and applications[J]. IEEE Transactions on evolutionary computation, 2004, 8(5): 425-442.

51. Goh C K, Tan K C. A competitive-cooperative coevolutionary paradigm for dynamic multiobjective optimization[J]. IEEE Transactions on Evolutionary Computation, 2009, 13(1): 103-127.

52. Zhang Q, Zhou A, Jin Y. RM-MEDA: A regularity model-based multiobjective estimation of distribution algorithm[J]. IEEE Transactions on Evolutionary Computation, 2008, 12(1): 41-63.
53. While L, Hingston P, Barone L, et al. A Faster Algorithm For Calculating Hypervolume[J]. IEEE Transactions on Evolutionary Computation, 2006, 10(1):29-38.

54. Said L B, Bechikh S, Ghdira K. The r-dominance: a new dominance relation for interactive evolutionary multicriteria decision making $[\mathrm{J}]$. IEEE Transactions on Evolutionary Computation, 2010, 14(5): 801-818.

55. Molina J, Santana L V, Hernndez-Daz A G, et al. gdominance: Reference point based dominance for multiobjective metaheuristics[J]. European Journal of Operational Research, 2009, 197(2): 685-692.

56. Thiele L, Miettinen K, Korhonen P J, et al. A preferencebased evolutionary algorithm for multi-objective optimization[J]. Evolutionary computation, 2009, 17(3): 411436.

57. G. Ruan, G. Yu, J. Zheng, J. Zou, S. Yang, The effect of diversity maintenance on prediction in dynamic multi-objective optimization, Applied Soft Computing 58 (2017) 631-647.

58. Li K, Deb K. Performance Assessment for PreferenceBased Evolutionary Multi-Objective Optimization Using Reference Points[J].

59. Zheng J, Yu G, Zhu Q, et al. On decomposition methods in interactive user-preference based optimization[J]. Applied Soft Computing, 2016.

60. Yu G, Zheng J, Shen R, et al. Decomposing the userpreference in multiobjective optimization[J]. Soft Computing, 2015: 1-17.

61. S. Jiang, S. Yang, A steady-state and generational evolutionary algorithm for dynamic multiobjective optimization, IEEE Transactions on Evolutionary Computation 21 (1) (2017) 65-82.

62. Helbig M, Engelbrecht A P. Benchmarks for dynamic multi-objective optimisation algorithms $[\mathrm{J}]$. Acm Computing Surveys, 2014, 46(3):1-39.

63. F. Wilcoxon, Individual comparisons by ranking methods, Biometrics bulletin 1 (6) (1945) 80-83. 